NBER WORKING PAPER SERIES

\title{
DOES STATE PRESCHOOL CROWD-OUT PRIVATE PROVISION? THE IMPACT OF UNIVERSAL PRESCHOOL ON THE CHILDCARE SECTOR IN OKLAHOMA AND GEORGIA
}

\author{
Daphna Bassok \\ Maria Fitzpatrick \\ Susanna Loeb \\ Working Paper 18605 \\ http://www.nber.org/papers/w18605 \\ NATIONAL BUREAU OF ECONOMIC RESEARCH \\ 1050 Massachusetts Avenue \\ Cambridge, MA 02138 \\ December 2012
}

This research was supported by a grant from the Institute of Education Sciences (R305A100574). We are grateful to Nathaniel Nakashima for providing excellent research assistance. Erica Greenberg provided invaluable help with Georgia Pre-K program data. We would also like to thank Angela Andrus and the other Census Bureau employees for their help with the restricted access Census data used in this project. The research in this paper was conducted while Bassok and Fitzpatrick were Special Sworn Status researchers of the U.S. Census Bureau at the California and New York Census Research Data Centers. Research results and conclusions expressed are those of the authors and do not necessarily reflect the views of the Census Bureau. This paper has been screened to ensure that no confidential data are revealed. All errors are the responsibility of the authors. The views expressed herein are those of the authors and do not necessarily reflect the views of the National Bureau of Economic Research.

NBER working papers are circulated for discussion and comment purposes. They have not been peerreviewed or been subject to the review by the NBER Board of Directors that accompanies official NBER publications.

(C) 2012 by Daphna Bassok, Maria Fitzpatrick, and Susanna Loeb. All rights reserved. Short sections of text, not to exceed two paragraphs, may be quoted without explicit permission provided that full credit, including $\odot$ notice, is given to the source. 
Does State Preschool Crowd-Out Private Provision? The Impact of Universal Preschool on the Childcare Sector in Oklahoma and Georgia

Daphna Bassok, Maria Fitzpatrick, and Susanna Loeb

NBER Working Paper No. 18605

December 2012, Revised October 2013

JEL No. I21

\begin{abstract}
The success of any governmental subsidy depends on whether it increases or crowds out existing consumption. Yet to date there has been little empirical evidence, particularly in the education sector, on whether government intervention crowds out private provision. Universal preschool policies introduced in Georgia and Oklahoma offer an opportunity to investigate the impact of government provision and government funding on provision of childcare. Using synthetic control group differencein-difference and interrupted time series estimation frameworks, we examine the effects of universal preschool on childcare providers. In both states there is an increase in the amount of formal childcare. While there is no crowd-out in Oklahoma, some of the government subsidized preschool in Georgia replaces childcare that would have occurred otherwise. We find the largest positive effects on provision in the most rural areas, a finding that may help direct policymaking efforts aimed at expanding childcare.

Daphna Bassok

University of Virginia

Ruffner Hall, 260

405 Emmet Street

Charlottesville, VA 22904

dbassok@virginia.edu

Maria Fitzpatrick

Department of Policy and Management

Cornell University

103 Martha Van Rensselaer Hall

Ithaca, NY 14853

and 4853

and also NBER

maria.d.fitzpatrick@cornell.edu

Susanna Loeb

524 CERAS, 520 Galvez Mall

Stanford University

Stanford, CA 94305

and NBER

sloeb@stanford.edu
\end{abstract}




\section{Introduction}

Governments often intervene to subsidize or provide goods and services that are considered to be under-provided in the private sector. For example, government involves itself in the provision of education, housing, health insurance and protection against crime. Theoretically, a major concern with government intervention of this type is that it will crowd-out private provision of a good or service, perhaps even rendering the overall amount of consumption to be the same with and without government intervention. If crowd-out occurs, valuable public resources may be being used inefficiently.

Efforts to find empirical support of the theoretical notion of crowd-out have been both relatively limited and mixed in their findings (Cutler and Gruber 1996; Card and Shore-Sheppard 2004; Gruber and Simon 2008; Payne 2009). Universal preschool policies introduced by states in recent years offer a novel and rich opportunity to investigate the impact of government subsidies on the private sector (Levin and Schwartz 2007). These universal preschool programs are large in scope, generally providing preschool services to all families with age-eligible children who want to enroll. Importantly, the programs we study, those in Georgia and Oklahoma, were introduced suddenly and widespread care quickly became available. In both cases the universal program was a distinct shift from the previously existing government subsidized preschool programs providing care to low-income families on a much smaller scale. Moreover, the childcare market is an interesting setting to examine how public subsidization affects private provision because the childcare sector is a mixed market (with private and public provision), has low barriers to entry, and is relatively less concentrated than other industries.

Beyond its use as an example of government intervention, understanding the full impact of government preschool provision is important in its own right, as early childhood educational 
interventions have received increasing attention as potential tools for improving child development and life outcomes for children and their families. For example, in his 2013 State of the Union address, President Obama put forward a proposal for Preschool-for-All, a federal program to incentivize state universal preschool programs like those in Georgia and Oklahoma. To date, the literature on early childhood interventions has focused largely on how government provision and funding affects child outcomes and family decision making (Schweinhart et al. 1993; Currie and Thomas 1995, 1999; Blau and Currie, 2004; Magnuson et al. 2004; Gormley and Gayer 2005; Gormley et al. 2005; Baker, Gruber and Milligan 2008; Fitzpatrick 2008, 2010; Cascio 2009; Herbst and Tekin 2010; Johnson, Ryan and Brooks-Gunn 2012; Cascio and Schanzenbach 2013).

However, the effect of interventions on these child and family outcomes likely depends in part on provider response to the government program. Specifically, the impact of any government investment in early childhood, either through direct provision or through funding only, will depend on the extent to which it leads to an introduction of new and/or higher quality services, rather than a supplanting of previously provided programs. We aim to fill a gap in the literature by examining the effects of universal preschool on the supply of providers. (Our outcome measures of the number of providers and employees in the childcare sector actually incorporate the intersection of supply and demand, but for brevity we refer to our data as measuring the supply side of the childcare market, as is conventional in the literature, e.g. Hotz and Xiao 2011). Throughout the paper, we make a distinction between universal preschool subsidization through provision, when the government opts to provide a good or service itself, versus subsidization through funding alone. 
Although evidence sheds light on how regulation, the other main tool for government intervention in the childcare arena, affects the supply of childcare (Ribar 1992; Blau 1993; Chipty 1995; Chipty and White 1997; Hotz and Kilburn 1997; Hofferth and Chaplin 1998; Currie and Hotz 2001; Blau 2003; Hotz and Xiao 2011), we know very little about the effects of government provision and funding on the childcare industry. ${ }^{1}$ This lack of understanding is in part because many of the most widely studied interventions have been too small in scope to produce general equilibrium consequences and in part because data sources needed to answer this question have only recently become available. More generally, little research has assessed the effects of government intervention through funding and provision on firms and workers, instead focusing on the effects on consumer decision making (Gruber and Simon 2008), charitable giving (Hungerman 2005) or on intergovernmental grants on government spending (Knight 2002, Gordon 2004). ${ }^{2}$ Recent exceptions focused on the crowd-out of supply include evaluations of crowd-out in postsecondary education (Cellini 2009), substance abuse treatment (Cohen, Freeborn and McManus 2013) and rental housing (Eriksen and Rosenthal 2010). Understanding how supply reacts to government intervention is important for understanding the welfare consequences of the intervention, including both the implications for affordability and access and measuring welfare changes that accrue to the providers themselves.

In this paper, we tackle two related but distinct research questions. First, we examine the effects of a state's introduction of universal preschool policy on childcare providers. To answer this question we use a differences-in-differences framework, incorporating both traditional and synthetic control group methods. Identification stems from comparing the supply of formal

\footnotetext{
${ }^{1}$ For a thorough review, see Blau and Currie (2006).

${ }^{2}$ Historically, this literature had trouble identifying a crowd out effect of government provision or funding, but more recent papers using more credible identification strategies have begun to find support for the crowd out theory. For a review, see Payne (2009).
} 
childcare (as measured using Census Bureau data on childcare providers) in states with universal preschool to that in states without universal preschool before and after the universal preschool policies were introduced. In both states there is an increase in the number of formal childcare providers; in Georgia the number of childcare providers increases by 25 percent, while in Oklahoma it increases by more than 30 percent. In this setting, therefore, government intervention seems to increase provision. Of interest is whether the increase is driven by pure expansion of the sector or if there is crowd-out, i.e. displacement of childcare that would have been provided in the absence of government intervention.

The state programs we study differ from each other in ways that could impact their effects on the industry. In Oklahoma, universal preschool is publicly provided and operates through the existing public school system. We consider Oklahoma a case of government provision of a good. In contrast, in Georgia, the programs have been set up as voucher-like subsidies where money from the state government follows children to the government-certified provider of their parents' choosing (either public or private). As a result, our comparison of the effects of universal preschool on the supply in these two states provides a case-study for understanding how government provision and government funding may have different effects on the supply side of a market.

Basic economic theory predicts that government provision of a good should result in decreased private expenditures on the good and may result in less overall consumption than government subsidization through funding alone (Peltzman 1973). This is because when the government provides a specific amount or type of a particular good, there may be additional costs to consumers (above the market price) of purchasing additional units. Consider the case we study here, universal preschool, where the government provides a set amount of care (three or six 
hours a day). In order to obtain daycare for a full workday shift (eight hours), parents have to piece together multiple arrangements, which may be more costly than the hourly cost of childcare (e.g. because of transportation costs). On the other hand, if the government only provides partial care, the private sector may survive if parents demand full workday care and private centers adjust to the new environment (e.g. by providing transportation or operating for different hours).

Moreover, with government provision a new competitor to the private sector is introduced. This addition may crowd out private provision of a good relative to an environment where the good is provided through private consumption and government funding. Therefore, despite being partly motivated by the goal of increasing the supply and use of a good, government provision may result in less use of a good, in part because of its effects on private providers. $^{3}$

We find that in Georgia, the overall increase in care is partly driven by an increase in the supply of formal childcare in the private sector and partly driven by new publicly-provided preschools. This makes sense, given that the government allowed both public and private providers to receive universal preschool funds. However, even though the formal childcare sector expanded, we estimate that at least 60 percent of the publicly funded universal preschool in Georgia took place in pre-existing private childcare settings. As such, there is substantial crowd-out of private consumption of preschool, a finding that is corroborated by evidence on enrollment (Fitzpatrick 2008). Meanwhile, in Oklahoma, the increase in childcare providers is driven by expansion in the public sector only, which concords with the flow of funds from the

\footnotetext{
${ }^{3}$ Government intervention is sometimes also motivated by increasing the quality of the good or service consumed. In what follows, we abstract from possible changes in the quality of childcare due to a lack of data. Understanding whether government funding and provision have differential effects on childcare quality is a valuable avenue for future research.
} 
state to public schools. Our results suggest that the resulting competitive pressure of this public sector expansion leads to little decrease in the number of private providers, but may have pulled workers from the private childcare providers into public preschools. As such, somewhat surprisingly, there is little crowd-out of private consumption of childcare in Oklahoma despite the fact that universal preschool is publicly provided.

Our second research question centers on understanding the effects of direct competition from the universal preschools on the supply of childcare at the market level. Specifically, we ask: does the presence of universal preschools in a neighborhood serve to increase the number of childcare providers (and their staff) in the market or does it crowd out existing centers and home daycare providers? To answer this question, we utilize two unique administrative datasets, one drawn from tax records on businesses operating in the childcare industry and the other from reported state spending and enrollment in universal preschool in Georgia and Oklahoma. Here, we use interrupted time-series methods that utilize variation across counties over time in the amount of universal preschool to estimate its effects on the overall number of providers as well as the number of private providers specifically.

We also use the market-level data to differentiate between different forms of crowd-out. The new providers could be all new universal preschool centers just added to the market on top of the existing childcare providers. Alternatively, new centers could partially crowd-out existing providers by either increasing the probability that they exit or decreasing the probability of nonuniversal preschool providers entering the market. We therefore examine how patterns of entry and exit of individual firms are altered by increased competition from universal preschool providers and find that existing firms are slightly more likely to exit when a new universal preschool provider enters a market in Georgia. Because we do not see a decrease in private 
sector activity with additional universal preschool providers in Georgia, this is suggestive evidence that public subsidization may increase churning in the private sector, perhaps by shifting the quality of providers in the market (though available data do not let us speak to the quality of providers).

The localized effects of universal preschool display similar patterns to those of the policies' introduction at the state level. For example, when a universal preschool center enters a county in Georgia, the overall formal care sector expands. About half of the expansion is driven by the public sector and half by private providers. As with the state-level analysis, we see this as evidence of crowd-out in Georgia because the market does not expand to the same degree as the expanded government-funded provision. Therefore, some universal preschool funded by the state of Georgia is crowding out preschool enrollment that would have happened otherwise.

Meanwhile, universal preschool driven expansion of the formal care sector in Oklahoma is driven exclusively by the public universal preschool providers. Moreover, although theory suggests government provision might crowd out private providers, we can rule out contractions of the private formal care sector in Oklahoma that are larger than one percent. Suggestive evidence supports the notion that what little crowd out occurs takes place through increased exit of existing providers. Since we measure childcare for all aged children and universal preschool is only available for four year olds, the lack of crowd out may be driven by the expansion of providers into care for different-aged children. Alternatively, the short hours of part-day care may make it possible for the private providers in Oklahoma to supplement the publicly provided universal preschool.

These more micro-level analyses also allow us to examine how the effects of universal preschool differ across communities with different populations. For example, we find that 
universal preschool had its largest effects on the formal childcare sector in the most rural areas and in places with low pre-existing levels of supply, a finding that may help direct policymaking efforts aimed at expanding the childcare sector.

In the next section, we describe the universal preschool programs in Georgia and Oklahoma. In Section III, we detail the data we use to answer each of the above questions. In Section IV, we describe our research design and the results for each question in turn before concluding the paper in Section $\mathrm{V}$ with a discussion of the implications of our results for policy.

II. What is Universal Preschool?

Before detailing our analyses, it is worthwhile to describe the universal preschool programs that we study in more detail, particularly because the implementation of universal preschool has been somewhat different across states. Georgia's Lottery for Education Act, passed in 1992, instituted a lottery which funds both the HOPE scholarship program and a prekindergarten initiative for four year olds. ${ }^{4}$ While initially both programs targeted low- and middle-income households, by 1995 , when lottery revenues exceeded expectations, the programs had expanded suddenly to include all age-eligible residents. In 2010, approximately 55 percent of four year olds were enrolled in Georgia Pre-Kindergarten (GPK) at a total state cost of $\$ 341$ million. In 1998, the Oklahoma legislature expanded its existing means-tested Early Childhood Program for Four Year Olds (ECPFYO) to include all age-eligible children regardless of income. By 2010, enrollment in the program reached 71 percent of four year olds and cost $\$ 167$ million. $^{5}$ Figure 1 details how enrollment in these programs grew.

\footnotetext{
${ }^{4}$ The HOPE scholarship has received much more attention from politicians and economists than its sister program, Georgia Pre-K. For examples, see Dynarski (2000) and Long (2004).

${ }^{5}$ http://nieer.org/yearbook/pdf/yearbook.pdf (March 13, 2007)
} 
In both states the programs are voluntary, free, and available to all children irrespective of family income. They operate for the length of the school year, but Georgia mandates a 6.5 hour day while Oklahoma offers both half- ( 2.5 hours) and full- (6 hours) day options. ${ }^{6}$ Educational requirements for teachers exceed those required for licensed child care facilities in both states. Similarly, both programs impose class size, ratio and curriculum regulations that exceed licensing requirements in their respective states. As such, universal preschool is generally of higher quality than most existing childcare.

A wide range of facilities can provide universal preschool care in both states, including public schools, Head Start centers, private child care centers, faith-based centers and other nonprofit centers. In practice however, the composition of providers differs substantially across the two contexts. The state of Georgia transfers lottery funds directly to centers. In Oklahoma, public school districts receive money from the general revenue allotted for the program on a first-come first-served basis. The districts may then provide the service themselves or contract out to child care centers that meet the state requirements. This stream of funding in Oklahoma has led to a much different mixed market structure than in Georgia. Indeed, while in Georgia only 20 percent of providers are public schools, in Oklahoma about 90 percent of the universal preschool slots are provided through the public school system. In both states, however, the care provided by the universal preschool program is considered formal classroom-based care for four year olds, a point to keep in mind as we describe the data and our results about the effects of universal preschool.

In 2010-2011, expenditures per child on universal preschool in Georgia averaged $\$ 4,298$, though actual reimbursement rates varied slightly based on location and teacher

\footnotetext{
${ }^{6}$ Both options in Oklahoma are free to parents but reimbursement rates to providers depend on the length of care provided. Both states encourage centers to offer additional care (after set program hours and during the summer). However, neither pays the cost of this "supplemental" care.
} 
education. In the same year, expenditures averaged $\$ 3,461$ per child in Oklahoma, though actual reimbursement rates depended on whether children attended full- or part- day sessions. ${ }^{7}$ To place the size of the subsidies in context, average child care costs for full-day center care for four year olds in the U.S. ranges from $\$ 3,900$ to $\$ 10,200{ }^{8}$

\section{Data on the Supply of Childcare}

To examine the effects of universal preschool on childcare providers, we utilize a number of data sources, including many that have never before been available for studying the childcare industry. First, to measure the number of and size of childcare centers and daycare homes (terms we define below), we use two data sources compiled by the U.S. Census Bureau from Internal Revenue Service tax return data: the Longitudinal Business Database (LBD) and the Integrated Longitudinal Business Database (ILBD). The former includes information on firms that have employees on payroll and the latter includes 'nonemployer' or 'owner operated' firms. ${ }^{9}$ Since childcare centers employ workers as teachers, directors, teacher's aides, etc. and home daycare settings are generally operated and staffed by a single person, we refer to the former group as childcare centers and the latter as family daycare homes. When combined, the two datasets provide us with information on any operating childcare business that filed tax returns in a given calendar year. ${ }^{10}$ We make a distinction between the formal and informal sectors, centers and

\footnotetext{
${ }^{7}$ http://nieer.org/yearbook/pdf/yearbook.pdf (October 28, 2011). Centers cannot receive more than a small registration fee from parents in either state.

${ }^{8}$ http://www.naccrra.org/randd/ (October 25, 2007)

${ }_{9}$ In the data, there is a distinction between establishments (single locations of operation) and firms (the overarching company, which may operate several establishments). Since most firms in the childcare industry are singleestablishment firms, we will use the terms firm and establishment interchangeably. Future work may distinguish between the two things, in part to determine whether universal preschool has caused a shift towards more multiestablishment firms.

${ }^{10}$ We subset to only those firms in the childcare industry according to their SIC or NAICS code. This means we may be missing childcare provided by employers in other industries (to the children of their own employees, e.g. hospitals, universities, etc.) and in churches. Additionally, these tax-return data are unable to capture anyone
} 
family daycare homes, respectively, because prior research suggests that formal center care is of higher quality, on average, than care in family daycare homes (Kontos, Hsu, \& Dunn, 1994).

Because IRS forms ask filers for slightly different types of information depending on whether they have employees or not, we have different information for different types of childcare providers. We use the information available to create the following outcome variables: number of private childcare centers, number of employees in private childcare centers, pay per employee in private centers, number of daycare homes, and total receipts for daycare homes. This information exists at the state-level for the period from 1990 to 2009 and at the county level for the period from 1990 to $2005 .{ }^{11}$ In what follows, we describe our other data sources in turn and the measures we create using each data source. The descriptions are of variables at the county level, which we then aggregate to the state level in our state-level analyses. The exception to this is that we do not conduct state-level analyses using the data on the informal sector because public-use data exist only for one year before universal preschool was introduced in Georgia, which renders the difference-in-difference identification strategy ineffective. Using restricted access data on daycare homes at the state-level produces similar results to the countylevel findings we present in Section IV, so we omit the state-level results on the informal sector in the next section. ${ }^{12}$

Our second resource for data is published information about the funding amounts and enrollment in universal preschool in Georgia. This information has been amalgamated from

\footnotetext{
working in this market who does not claim income for doing so (i.e. not filing a 1040 Schedule C). Those missing are most likely to be babysitters, nannies and relatives providing care "off the books."

${ }^{11}$ The state-level data on childcare businesses comes from aggregating the County Business Patterns and the Nonemployer Statistics, which are published data derived from the Business Register of all operating business in the U.S. These public data are available for the whole time horizon from 1990-2009. Because some of our county-level analyses utilize direct links of businesses with our other data using name and address information, we limit our county-level sample to the period over which the restricted-access data containing this information is available, 1990-2005.

${ }^{12}$ Results are available from the authors upon request.
} 
several sources, including historical government publications and more recent administrative data which the state's universal preschool administrators, the Department of Early Care and Learning, shared with us. ${ }^{13}$ Using these data, we create measures of the penetration of government-funded universal preschool in a community in a given year: the number of childcare centers receiving universal preschool funds in a county and the number of universal preschool funded classrooms in a county.

Third, we construct comparable data on universal preschool in Oklahoma. Because in Oklahoma universal preschool is provided through the public school system, we use public school enrollment information from Common Core of Data (CCD) to construct measures of the diffusion of government provided preschool. ${ }^{14}$ The CCD collects information on enrollment by grade in public schools and we aggregate this information to construct the following measures: the number of schools in each county that provide universal preschool and the number of universal preschool classrooms in the county. ${ }^{15}$ These are comparable to the number of centers and classrooms per county in Georgia.

In addition, many other states offer pre-k programs targeted at low-income or learning disabled students (in 2011, 39 states offered such programs, Barnett et al. 2011). We therefore also use the CCD to measure the amount of pre-k enrollment occurring in schools in other states.

\footnotetext{
${ }^{13}$ Depending on the year, the data include measures of enrollment in or funding provided to each universal preschool program. We use annually reported per-child funding measures to translate between enrollment and funding. Note that the data are not available to construct these measures for the 1996 and 1997 school years, so we drop these years from the analysis.

${ }^{14}$ Because a small fraction of the enrollment (10 percent) in Oklahoma universal preschool occurs in private centers arranged by the school districts, we were concerned that the CCD data would not capture all universal preschool enrollments in Oklahoma. However, detailed information about the prevalence of community provider based care is not available. We therefore cross-checked the total enrollment in the CCD with the total enrollment as reported by the state's Department of Education. The measures of total enrollment match, making us confident that the CCD info accurately measures the extent of universal preschool in Oklahoma. However, since school districts are reporting enrollment they contract out to local providers, we may be slightly overstating the amount of public provision.

${ }^{15}$ The number of schools in a county providing preschool is the count of the individual schools with at least 1 child enrolled in preschool. The number of classrooms is computed by taking the number of children in a school divided by 18 , the class size limit, and aggregating the number of classes at all the schools in a county.
} 
We combine the CCD and the LBD to get measures of the total number of formal centers and classrooms, both public and private, in each county in states without universal preschool. Note that we also use this combined CCD and LBD data to measure the size of the formal sector in Georgia prior to when the universal preschool program was introduced.

To summarize, we create several measures of childcare provision at the state and county level that we believe proxy for the amount and type of childcare in the market. As a measure of the overall supply of formal childcare we use the total number of both public and private childcare centers and their employment. If universal preschool increases preschool take-up, one or both of these measures should increase upon universal preschool introduction. ${ }^{16}$ To capture the role of the private sector in the provision of formal childcare, we use the number of private centers and employees. If the public universal preschool programs crowd-out the private provision of formal care, we should see a decrease in these measures. To capture the role of the private sector in informal childcare, we use the number of family daycare homes. Finally, because prior work has linked the pay of childcare workers to the quality of care provided, we use the pay per employee in private childcare establishments as a loose proxy for the quality of those centers (Whitebook and Sakai, 2003; Shonkoff and Phillips, 2000).

Our data offer some distinct comparative advantages over other data that has been or might be used to study the crowdout driven by government intervention into the preschool market. First, few surveys collect information about childcare use and what survey data exist are limited in sample size and types of childcare covered. ${ }^{17}$ Our data cover the universe of childcare

\footnotetext{
${ }^{16}$ Of course, if providers were operating below full capacity, childcare consumption could increase without any of these measures changing.

${ }^{17}$ For example, the Decennial Census, the survey with the greatest number of respondents, asks parents only whether their child attends preschool, but has no other questions about childcare. The Survey of Income and Program Participation includes more detailed questions about childcare use, but the samples are relatively small and surveys are only done every few years.
} 
providers and allow us to examine how government intervention into care for four year olds affects childcare providers more generally. The welfare effects of government intervention differ if a provider is forced out of the market entirely rather than if she just changes the age of children in her care. Second, surveys contain questions posed to respondents about their childcare providers. This likely renders some information inaccurate. For example, a business is more likely to accurately report their acceptance of public sector funds than a parent is to know whether the center received subsidy income for the children other than her own. Despite these advantages, our data are somewhat limited because they lack information about the quality of childcare centers or the prices paid for care. Such rich data are scarce, and to our knowledge, data with such information does not exist that would allow for an analysis of universal preschool.

The average and standard deviations of the supply measures across counties in Georgia and Oklahoma are reported in Table 1. Both states have similar distribution of formal childcare centers across their counties, but the counties in Oklahoma seem to have more daycare homes, on average, than those in Georgia. In contrast, the formal daycare centers in Georgia have higher levels of employment than those in Oklahoma.

\section{Determining the Effects of Universal Pre-Kindergarten Identifying the Effects of a Statewide Universal Pre-Kindergarten Policy}

In the first of our analyses, we are interested in identifying the effects of a state government's introduction of a universal preschool policy on the supply of childcare in the state. Note that universal preschool introduced in these states was layered on top of an existing network of state and federal child care and early education programs, such as Head Start. For this reason, the question we answer is: what is the effect of the introduction of a universal 
preschool policy on the supply of childcare above and beyond the effects of preexisting government involvement? Given the existing landscape, we consider this the most relevant policy question. The assumption underlying our use of the difference-in-difference strategies detailed below to answer this question is that the universal preschool policies in Georgia and Oklahoma were orthogonal to any other changes in the childcare sector in these states (relative to the states in the comparison group). ${ }^{18}$

Although the universal preschool policies in the two states are generally similar, they differ in one important dimension. Georgia's program operates much more like a voucher system, where any type of provider can apply to run a universal preschool classroom (provided they meet certain requirements) and will receive funding directly from the state. The Oklahoma system, on the other hand, operates largely through the public school system because the funds flow through the local school districts. Following Peltzman (1973), we hypothesize these differences in program design may lead to differences in the effects of the program on firms and employees and therefore we separate this analysis by state. Although there are other differences between Georgia and Oklahoma that may also lead to differential effects of a universal preschool program, we use the comparison of effects in the two states as a case study for comparing government funding alone to government provision.

Our empirical strategy leverages the exogenous introduction of universal preschool programs in Georgia in 1995 and in Oklahoma in 1998 in a differences-in-differences framework. We do this first by estimating the following equation:

$$
Y_{s t}=\alpha+\beta X_{s t}+\theta U P \operatorname{KinG} A_{s t}+\gamma U P \operatorname{KinOK} K_{s t}+\delta_{s}+\vartheta_{t}+\varepsilon_{s t}
$$

\footnotetext{
18 For confirmation that universal preschool introduction is not confounded by expansions in other government
} programs, like Head Start, see Fitzpatrick (2008). 
Equation (1) represents a traditional differences-in-differences framework, in which $s$ indexes the state and $t$ the year of the observation. There are controls for state $(\delta)$ and year $(\mathcal{Y})$ fixed effects. $Y$ represents an outcome variable from our set of measures of the supply of childcare detailed in the previous section, e.g. the total number of formal care providers. The variables UPKinGA and UPKinOK are dummy variables that take a value of one once the universal preschool policy is introduced in Georgia and Oklahoma, respectively.

The identification assumption underlying our use of this specification is that nothing else changed in these states concurrent with the introduction of universal preschool. To reassure ourselves that this is the case, we also control for time-varying factors that might be related to childcare provision, such as spending on other childcare subsidies and Head Start, the unemployment rate, the employment rate of women in the state, the number of children of school age, the number of children ages zero to five, the racial composition of residents, the poverty rate and median income of residents. ${ }^{19}$ The standard errors are clustered at the state level in order to allow for the possibility of serially correlated errors.

Because we estimate the relationship between universal preschool introduction and the supply of childcare separately for each state, we essentially have two case-studies of universal preschool introduction. The extent to which our model can be used to estimate the causal impact of universal preschool introduction depends on identification of a comparison group that accurately captures the counterfactual supply of childcare in Georgia and Oklahoma in the absence of universal preschool introduction. We present results using three comparisons: (1) all

\footnotetext{
${ }^{19}$ Additionally, we could control for state specific trends in the outcomes, which we did in previous versions of the paper. However, a visual examination of the data (see Figures 3, 4 and those in Appendix A) suggests controlling for time trends over-fits the data by parsing some of the treatment effect into the trend. Also, our synthetic control group method explicitly controls for differences in trends by creating a control group with a trend in the outcome variable that most closely mirrors the trend in the outcome in the treated state. As such, we only present results here without state specific trends, but estimates from specifications with trends are available from the authors upon request.
} 
others states; (2) Southern states (under the hypothesis that patterns of childcare demand are similar in Georgia, Oklahoma and other Southern states); and (3) a synthetic control group. Synthetic control group methods were recently introduced for estimating the effects of an intervention that has been given to only one treatment group, in this case only to one state (Abadie et al. 2010). In our application, this requires creating a synthetic control group for each of our two universal preschool states that best approximates the counterfactual supply of childcare in these states in the absence of universal preschool and the pre-treatment evolution of other characteristics that may be related to the supply of childcare.

Following Abadie et al., we create synthetic control groups for Georgia and Oklahoma by picking the weighted combination of all other states that minimizes the mean squared prediction errors of the outcome variables and a set of observable characteristics in the pre-intervention period. ${ }^{20}$ More specifically, we define $X_{I}$ as a vector of observable characteristics in Georgia (or Oklahoma) before universal preschool is introduced and $X_{0}$ is the matrix of these characteristics in other states. We choose a vector of weights, $W$, that minimizes the following function, which represents the distance between the pre-treatment characteristics of Georgia and the other states:

$$
\left\|X_{1}-X_{0} W\right\|_{V}=\sqrt{\left(X_{1}-X_{0} W\right)^{\prime} V\left(X_{1}-X_{0} W\right)} .
$$

In what follows, we choose a matrix, $\mathrm{V}$, that assigns weights to the pre-treatment outcomes and characteristics in order to minimize the mean squared prediction error in the pre-treatment period. We conduct inference by randomly assigning treatment status to each state in the country that does not have universal preschool, conducting synthetic control group analyses using each

\footnotetext{
${ }^{20}$ Control group weights are available from the authors upon request. We use each outcome individually when creating the synthetic control group for the analyses using that outcome as the dependent variable. The results are qualitatively similar when we use all pre-treatment outcome measures simultaneously to create a synthetic control group. The observable characteristics that we use in the creation of the synthetic control groups are consistent over all of the analyses and include population size, age and racial composition of residents, income levels, unemployment rates, etc.
} 
assigned 'placebo' treatment in turn, and obtaining coefficient estimates. The distribution of these 'placebo' treatment coefficient estimates serves as the distribution for assigning p-values of statistical significance to our synthetic control group estimates.

\section{Universal Preschool in Georgia}

A visual inspection of childcare supply measures over the period suggests that universal preschool had a positive effect on the amount of childcare being provided in Georgia. Figure 2 plots the total number of childcare centers (Panel A), number of employees working at childcare centers (Panel B), the total number of private childcare centers (Panel C), number of employees working at private childcare centers (Panel D), and the amount of pay per employee (in thousands of $\$ 2010$, Panel E) over the period studied. The solid black lines in each panel measure the outcome for Georgia, while the dashed black lines plot the outcome for the synthetic control group. ${ }^{21}$ The vertical line in each figure represents the first year in which universal preschool was implemented in Georgia, 1996.

Panels A and B, suggest that the introduction of universal preschool increased the overall formal childcare sector both in terms of the number of centers and employees in Georgia relative to the number of centers and employees in the synthetic control group. The former increased by about 25 percent, while the latter increased by about 33 percent. The increase in the private sector, meanwhile, was less dramatic (Panels $\mathrm{C}$ and $\mathrm{D}$ ). The number of private childcare centers hardly increased, but the number of childcare workers in private centers increased by 25 percent. Finally, the annual earnings per childcare worker remain similar in Georgia and the synthetic

\footnotetext{
${ }^{21}$ The patterns of childcare supply described in Figures 2 and 3 using data on synthetic control groups closely mirrors the patterns that emerge from comparisons of childcare supply in Georgia and Oklahoma with the supply in the rest of the Southern States (Appendix A). The similarity is also confirmed in estimates presented in Tables 2 and 3.
} 
control group over the period. These results suggest that universal preschool in Georgia increased the amount of formal childcare taking place in the state by increasing the amount of both publicly and privately provided care.

Of importance, however, is whether these estimated effects of universal preschool introduction are statistically different from zero. In Table 2 we present results, first for a set of traditional difference-in-difference specifications, then using the synthetic control group methods. In column (1), we present the results from equation (1) using the 48 other states as a control group. The estimates suggest that universal preschool increased the amount of formal care in Georgia by increasing the overall number of private and public centers (by 244 centers or an additional center for every 450 four year olds) and the amount of employment in centers (by 5,531 employees or one additional employee for every 20 four year olds).

The estimates in column (1) also suggest that universal preschool in Georgia had a positive effect on the private formal care sector. For example, the estimates in Panel D show that universal preschool increased the number of employees in private child care centers by between 5,165 employees (the estimate is statistically significant). The estimated positive effect on the private sector is not always statistically significant, however. For example, although the statistically significant estimate in Panel C of column (1) suggests that universal preschool in Georgia increased the number of private childcare centers by 68 facilities, the estimate is not statistically significant at conventional levels.

The childcare utilization of families in Georgia may be very different than that in other parts of the county, like the northeastern states. ${ }^{22}$ Therefore, in column (2), we repeat the estimation using only the other states in the Census Bureau-defined South as the comparison

${ }^{22}$ http://nces.ed.gov/pubs2005/2005099.pdf (Accessed March 8,2012) 
group. The expansion in the formal care sector is evident in the estimates in Panel A and B of

Table 2 and the estimates are statistically indistinguishable from those in Columns (1).

The synthetic control group estimates of the effects of universal preschool in Georgia are presented in column (3) of Table 2. These estimates, which are our preferred specification because of the close match between pre-treatment outcomes and other characteristics in the treatment and synthetic comparison states, show that the universal preschool policy increased the overall formal sector by 374 establishments and 5,443 employees. Inference in the synthetic control group method compares the predicted effect of universal preschool using the actual treated state and its synthetic control group to the estimated effect of universal preschool in placebo tests. ${ }^{23}$ Both of these estimates are statistically significant at the 5 percent level and are close to the traditional difference-in-difference estimates reported in the previous columns.

At the same time, universal preschool increased the number of private establishments by 6 (though this is not statistically significant at the 10 percent level). The total number of employees at private childcare centers increased by 4,059 , an estimate that is statistically significant at the 5 percent level. Therefore, it appears that universal preschool increased the overall amount of formal childcare in Georgia by increasing the number of both public and private providers and by increasing employment levels in both sectors. Using the estimates in column (3), the public sector expanded by 368 centers and 1,384 workers and the private sector expanded more on the intensive margin, adding just 6 centers but 4,059 additional workers. (Note that the confidence interval on the number of private providers is wide.)

\footnotetext{
${ }^{23}$ As previously described, the placebo tests involve taking each contributing member of the control group in turn and creating a synthetic control group as though it were the treated state. The predictability (mean square prediction error) of each of these placebo tests for the pre-treatment period is compared to its predictability in the post period. If there really were a shock effect of universal preschool the model should do less well at predicting the outcomes in Georgia in the pre-period relative to the post-period than it does in each of the other states. We conduct these placebo tests for each outcome in each of the other 49 states in our sample and determine statistical significance using the fraction of control group states that have a larger MSPE ratio (post-period to pre-period) than Georgia.
} 
Though the number of government funded pre-k providers in Georgia was about 1,700 in 2005 (Figure 1), our estimates suggest the introduction of the universal preschool policy increased the overall number of childcare centers in the state by just 374 . Therefore, universal preschool expanded the formal childcare sector, but the majority of the publicly funded preschool took place in schools and centers that either existed before the introduction of universal preschool took place (and the source of funds switched from parents to the state) or are new publicly funded centers that forced out the previously existing centers. We return to this issue in later analyses, detailing trends in the entry and exit of individual firms, which gives us more traction on what took place.

\section{Universal Preschool in Oklahoma}

Figure 3 presents the number of childcare centers, employees in those centers and payroll per employee for Oklahoma and its synthetic control group. The figures show a distinct increase in the number of formal childcare centers of 30 percent (public and private combined, Panel A) but almost no change in the number of their employees (Panel B). Visually, it appears that universal preschool in Oklahoma may have had a small positive, perhaps temporary, effect (4 percent, Panel C) on the number of private childcare centers while decreasing the number of workers in the private sector by about 16 percent (Panel D). As with Georgia, there was essentially no change in the payroll per employee (Panel E). These results indicate that while universal preschool increased the number of entities providing formal childcare in Oklahoma, it may have resulted in a contraction of the private sector as workers moved from private childcare centers to the new universal preschool classrooms in public schools. Because the overall number of centers does not change, this would imply smaller childcare centers. 
To determine whether this is the case, we turn to our methods for inference presented in Table 2. Since the results of the synthetic control group method are our preferred estimates, we focus the discussion on the estimates in column (3). These suggest that the introduction of universal preschool in Oklahoma led to an increase of 448 formal childcare establishments, an estimate that is statistically significant at the 10 percent level and consistent with evidence using other estimation specifications. The estimated effect on the number of workers in the private sector is a sizeable decrease of 1,293 workers, though the estimate from our preferred specification is statistically indistinguishable from zero at conventional levels. Since there was no concurrent decrease in the total number of employees (Panel B), this may suggest that some of the workers in the formal private sector moved to the newly expanded publicly provided programs.

\section{Identifying the Effects of a Local Universal Preschool Implementation}

While the effect of the introduction of a universal preschool policy is one question of interest, we are also interested in examining the effects of the competition from governmentfunded preschool on the supply of childcare at a more micro level. Specifically, we are interested in whether government-funded preschools in a market serve to crowd out the childcare that was already being provided in the market or whether they expand the existing childcare opportunities for residents. This analysis is valuable for two reasons. First, it allows us to determine whether the expansion of care was widespread or concentrated in places that actually saw increases in government subsidized preschool. Second, using the more micro county-level analyses, we are able to look for differences in the effects of universal preschool subsidization 
across different types of communities, such as by income levels, racial composition and population density.

To answer this question, we use county-level data on the outcomes in Georgia and Oklahoma described above. ${ }^{24}$ Because of the differences in policy design, we analyze each state separately. Here, our estimation strategy is the following:

$$
Y_{c t}=\alpha+\beta X_{c t}+\gamma U P K_{c t}+\delta_{t}+\theta_{c}+\pi_{c} t+\varepsilon_{c t} .
$$

That is, we regress outcome $Y$ of county $c$ in year $t$ on our variable of interest, $U P K_{c t}$. In Georgia, universal preschool is defined as the number of government-funded centers in operation in a given county in a given year. In Oklahoma, universal preschool is defined as the number of government-operated centers (i.e. schools with universal preschool) in operation in a given county in a given year. ${ }^{25}$ In addition, we control for county $(\theta)$ and time $(\delta)$ fixed-effects in all specifications.

To interpret our estimated effect of the number of universal preschool centers on childcare supply as causal requires that the timing and scale of universal preschool provision in a county is uncorrelated with other factors that are likely to drive childcare supply in the market, net of the other controls in the model. For this reason, in some specifications, we include a host of control variables in order to capture time-varying market characteristics $\left(X_{c t}\right)$ that may be

\footnotetext{
${ }^{24}$ Readers may be concerned that a county is not a small enough geographic area to appropriately proxy for a market. However, there are 159 counties in Georgia and 77 in Oklahoma, which means we are less concerned about our geographic proxy for a market than if we were using other states that had fewer counties. We are able to conduct some of our analyses (those using the LBD data) at the tract level and the results are qualitatively similar, though slightly larger in magnitude. This concords with the notion that new firms will have the most impact on the firms and workers closest to them.

${ }^{25}$ In Oklahoma, the public preschool enrollment comes from the Common Core of Data, in which is recorded the number of children who live in a school district and who are enrolled in universal preschool, whether the preschool classroom is housed in that particular public school or in a childcare center in the school district. To come up with a measure of universal preschool provision that most closely mimics our measure in Georgia, we count the number of schools who record positive enrollment. We tested alternative measures of universal preschool enrollment, including the number of preschool classrooms in a county, the percent of four year olds in the county who were enrolled in universal preschool, etc. The results are much noisier with these other measures, but show mostly the same patterns of effects in Georgia and Oklahoma.
} 
driving childcare supply, including spending on other childcare subsidies and Head Start, income levels, unemployment rate, racial and age composition of residents and various school characteristics. We also always include county-specific time trends to capture any other unobserved characteristics that are changing steadily over time, such as a change in preference for childcare use. When the model includes the full set of controls, the effects of universal preschool provision are identified off of deviations from the trend in the number of universal preschool centers that are correlated with deviations from trends in the number of childcare centers, employees, etc. Any bias in our estimates would have to stem from systematic endogenous universal preschool location choices that are orthogonal to the entire set of timevarying controls we use. Given the rich set of controls we use, which include measures of demand such as subsidy funding, population size, income and employment, there is limited scope for such bias.

The results of these county-level analyses are in Tables 3 and 4 for Georgia and Oklahoma, respectively. In each table, we report coefficient estimates from two specifications, each with state and year fixed effects: one with county-specific time trends (Column 1) and one with these trends and time-varying community characteristics (Column 2). In both states, an additional universal preschool center in the county leads to an increase in the amount of formal care, but the effects on private provision in the formal and informal sectors is mixed. In what follows, we interpret the estimates on the fully saturated model (Column 2).

In Georgia, the increase in formal childcare is 0.39 centers for each universal preschool center. The addition of one universal preschool facility is also associated with a 0.23 increase in the number of private formal centers. (These estimates are quite stable across specifications, though not always statistically significant.) These estimates lead us to conclude that about 61 to 
77 percent of the universal preschool subsidization is paying for childcare that would have taken place even in the absence of Georgia's subsidization.

Also, the addition of another government funded preschool in a Georgia county appears to increase the number of both public and private employees in the county by two workers, though the results are not statistically significant. Wages, however, are hardly affected by increased competition from universal preschool providers within the county. Combined, the results suggest that universal preschool funding expanded the use of formal care by expanding both the public and private sectors. As with the state-level analyses, based on these estimates, it is difficult to tell whether the growth of the childcare industry was driven by pure expansion or reshuffling of the private market. We return to this later.

Turning to Table 4, in Oklahoma, a new universal preschool center (i.e. a school that is newly providing universal preschool) leads to an increase in the number of formal care establishments by almost exactly one (the coefficient is 0.96 and is statistically significant at the 1 percent level). This increase is not connected to a large decrease in the number of private childcare centers (the coefficient is just -0.04). In fact, given the standard error of 0.05 , we can rule out scenarios in which the publicly provided centers decrease the number of private daycare centers of more than 0.14 centers for each universal preschool providing school. Since there are approximately 800 schools providing universal preschool in Oklahoma, this means that about 100 private childcare centers do not exist because of universal preschool. This represents less than one percent of the childcare centers in Oklahoma before its universal preschool policy came into place. In Oklahoma, public provision did not lead to a significant contraction in the private formal childcare market, though it may have led to a decrease in the size of existing private centers by encouraging employees to migrate to the public sector. (Just as at the state level, the 
results of market level analyses in Table 4 suggest that an additional public provider of preschool leads to decreases in the number of workers in private childcare centers, but little change in the number of employees in sector overall.)

Finally, the estimated effects of universal preschool expansion on informal daycare homes are also reported in Tables 3 and 4. In both states, the estimates suggest universal preschool may have led to contraction in the informal market. However, in results not presented here, these estimates bounce around a good deal, changing sign and magnitude depending on the set of included control measures. Additionally, the standard errors are generally quite large, often rendering the estimates statistically insignificant. This is in contrast to the results using information on childcare centers and could be for one of two reasons. First, the informal sector may fluctuate more than the formal sector. The barriers to entry are lower because the regulations regarding inputs are usually less stringent. It also may be easier to start or close a business without any employees than it is to hire and fire workers. Second, and perhaps more relevant for our current setting, the data on the informal sector may be noisier. The tax-return data we use may not be good at capturing the actual operation of such nimble firms if they are less likely to consistently report income and operation. For this reason, we do not make much of the results using the informal childcare measures.

\section{New Entry or Crowd Out?}

The results we have presented so far suggest that the private formal sector expands when the government uses its funding, rather than provision, as the mechanism of subsidizing universal preschool. Moreover, there appears to be little, if any, negative effect of public universal preschool funding or provision on the private formal childcare sector (i.e. there are no 
statistically significant signs of contraction of providers or employees). Of interest, however, are the competitive dynamics underlying these results. One extreme possibility is that all of the universal preschool providers are providers who were in existence already as private childcare centers but have switched their funding source. Such a scenario would be considered complete crowd-out. We can tell that this extreme story is not true in either state because our estimates show that in both states additional universal preschool providers lead to increases in the size of the formal childcare sector. Furthermore, a close look at the providers entering the universal preschool program in Georgia in its first few years of existence shows that about 65 percent were new providers in the market. $^{26}$

Given that we know universal preschool increases the amount of formal childcare provision, there are two other possible scenarios. The new providers could be all new universal preschool centers just added to the market on top of the existing childcare providers. The above descriptive information from Georgia suggests this is not the case. Alternatively, the new centers could partially crowd out existing providers by either increasing the probability that they exit or decreasing the probability of non-universal preschool providers entering the market. Given constraints on the available data, it is difficult to measure the extent to which either of these scenarios is true, but we now detail two attempts to investigate these dynamics further.

We estimate models of individual firm behavior in Georgia and Oklahoma. For example, we estimate the following equation:

$$
\text { Entry }_{i c t}=\alpha+\beta X_{c t}+\gamma N e w U P K_{c t}+\delta_{t}+\theta_{c}+\varepsilon_{i c t}
$$

In equation (3), the outcome is entry of firm $i$ in county $c$ in year $t$, but we also run the analysis using firm exit. Operationally, we define a firm to have entered the market if it was not in

\footnotetext{
${ }^{26}$ Based on matched UPK administrative and LBD data. Because of the available data, we used name and address to match firms across data sets, which produces a match rate of approximately 75 percent.
} 
existence in the previous year, $t-1$, and to have exited if it is not in existence in the following year, $t+1$. The universal preschool measure in this equation is the number of new (previously non-existent) universal preschool providers in the county between the current and previous years.

The results of estimating this equation using both entry and exit as the dependent variables for the firms in both Georgia and Oklahoma are in Table 5. The addition of a new universal preschool funded center in Georgia is associated with a decrease in the probability of new firms entering ( 0.01 percentage point decrease in the probability of entry) and a small increase in the probability of firms exiting (0.04 percentage point increase). The estimated effect on entry is too noisy to be statistically significant at conventional levels. However, the estimated effects on exit are statistically significant and suggest that, on net, universal preschool funding in Georgia led to a fifteen percent increase in the propensity of existing firms to exit. This is supportive evidence of some crowd out of existing firms rather than of new universal preschool providers purely being added to the existing supply. Universal preschool provision in Oklahoma had similar effects on entry and exit, though the estimates are smaller and not statistically significant at traditional levels.

\section{How Does the Effect Differ Across Communities?}

Previous research points to different patterns of childcare use that are associated with community residents' race, income levels and their population density (Fuller, Loeb, Strath, \& Carrol, 2004; Bassok, Fitzpatrick, Loeb, Paglayan 2012). To investigate whether universal preschool may have had differential effects across communities with different types of residents, we re-estimate equation (2) and include interaction terms between quintile dummies for various community characteristics and the universal preschool measure (as well as the quintile dummies 
themselves). Specifically, we separate counties based on the following four characteristics:

percent of residents who are African American, median household income of residents, percent of residents residing in rural areas, and the number of LBD establishments in existence at the beginning of the period. We chose the first two characteristics because previous research has shown that families of different races utilize childcare in different ways and because, for predictable reasons, income is linked to the use of paid childcare. We include the last two characteristics because the effects of government intervention in an industry may depend on the existing amount of supply in the industry, which differs in urban and rural areas.

The results for Georgia using the latter two characteristics are in Table 6. We did not find any patterns of statistically significant differences in the effects of universal preschool expansion across the first two community characteristics in Georgia or any of the community types in Oklahoma, so we omitted the results in the interest of brevity. ${ }^{27}$ Note that we included each set of community characteristic interaction terms in separate regressions. For each outcome, we report the coefficient estimates from two specifications, one with just the countyspecific time trends and one with these trends and the time-varying observable characteristics of the county. All specifications in these tables include county and year effects. ${ }^{28}$

The results in Panel A suggest that universal preschool has the largest effects on the amount of childcare centers and employees in the most rural areas of Georgia. In Panel B, we see that this is likely connected to the fact that the most rural areas are those with the least number of daycare centers at the beginning of the period. In places where supply was low before universal preschool was introduced, universal preschool has the largest impacts on the number of

\footnotetext{
${ }^{27}$ These estimates are available from the authors upon request.

${ }^{28}$ We have not reported any results using information about family daycare homes because of the apparent noisiness of that data. Additionally, because the estimated effects on payroll per employee in childcare centers are negligible, we have omitted them here. They are available from the authors upon request.
} 
both public and private childcare providers. However, in counties that had the most providers before universal preschool was implemented, the expansion of the formal care sector occurs only through expansion of public providers, not through increased numbers of private providers.

\section{Conclusion}

In this paper, we have detailed the effects of publicly funded and publicly provided preschool, both in terms of the macro-level natural experiment of policy introduction and in terms of the market level effects associated with increased direct competition. Some consistent patterns emerged that are likely linked to the design of the governments' intervention into the early childhood care and education market. First, government funding of universal preschool in Georgia led to increases in the number of childcare providers in the formal sector that were likely driven by increases in both the number of public and private centers operating. Despite the fact that three-fourths of the government funded preschool takes place in the care of pre-existing providers, the childcare sector in Georgia expanded by nearly 20 percent.

Second, publicly provided preschool in Oklahoma led to increases in formal childcare in the state, largely driven by increase in preschools within schools. We show that this expansion in public provision of classroom-based preschool for four year olds did not lead to contraction of the private formal classroom-based sector for all ages of children. Whether this is because the additional preschool care was added to the market in addition to the existing preschool care for

four year olds or because private providers were able to move into caring for children of different ages will require research using data that is yet unavailable.

The differences in the effects of universal preschool across these two states is likely driven by the subsidization mechanism chosen for the universal preschool program. 
Subsidization through government funding alone, as in Georgia, likely encourages private provision more than government provision. Because the two states are case-studies, we cannot rule out that there are other differences between them that drive the differences in effects of universal preschool. However, the localized estimates of the effect of universal preschool expansion control for differences in characteristics. Therefore, this empirical evidence is a crucial first step in understanding the effects of government provision and funding of goods and services on the supply side both in the childcare sector and the economy more broadly.

Finally, we present new evidence on the differential effects of government subsidization of childcare in rural and urban communities. Our results suggest that government subsidization expands the supply of childcare the most in communities that have low levels of supply. In the states we studied, rural areas had the least amount of childcare and saw the greatest expansion in childcare with the introduction of universal preschool. This is an important finding for policymakers to keep in mind when designing policies for government subsidization and for educational interventions more broadly. 
References

Abadie, Alberto, Alexis Diamond, and Jens Hainmueller. 2010. "Synthetic Control Methods for Comparative Case Studies: Estimating the Effect of California's Tobacco Control Program.” Journal of the American Statistical Association, 105 (490): 493-505.

Michael Baker \& Jonathan Gruber \& Kevin Milligan, 2008. "Universal Child Care, Maternal Labor Supply, and Family Well-Being," Journal of Political Economy, University of Chicago Press, vol. 116(4), pages 709-745, 08.

Barnett, Steven W., Cynthia Lamy, and Kwanghee Jung. 2005. "The Effects of State Prekindergarten Programs on Young Children's School Readiness in Five States." Rutgers University: National Institute for Early Education Research.

Bassok, Daphna, Maria Fitzpatrick, Susanna Loeb, and Agustina S. Paglayan. 2012. "The Early Childhood Care and Education Workforce in the United States: Understanding Changes from 1990 through 2010." http://cepa.stanford.edu/sites/default/files/AEFP_ECCE\%20Workforce.pdf.

Blau, David M (1993), “The Supply of Child Care Labor", Journal of Labor Economics 11 (2): 324-347.

Blau, David M. (2003), “ Unintended Consequences of Child Care Regulations”, unpublished paper (University of North Carolina, Chapel Hill).

Blau, David, and Janet Currie. 2006. "Pre-School, Day Care, and After-School Care: Who's Minding the Kids?" In Handbook of the Economics of Education, edited by Eric Hanushek and Finis Welch, 1163-1278. Amsterdam: Elsevier Science.

Card, David and Laura Shore-Sheppard. 2004. "Using Discontinuous Eligibility Rules to Identify the Effects of the Federal Medicaid Expansions on Low Income Children." Review of Economics and Statistics, 86(3): 752-766.

Cascio, Elizabeth. 2009. "Maternal Labor Supply and the Introduction of Kindergartens into American Public Schools." The Journal of Human Resources, 44(1), 140-170.

Cellini, Stephanie Riegg, 2009. "Crowded Colleges and College Crowd-Out: The Impact of Public Subsidies on the Two-Year College Market," American Economic Journal: Economic Policy, 1(2), August 2009: 1-30.

Chipty, Tasneem and Ann D. Witte (1997), An Empirical Investigation of Firms' Responses to Minimum Standards Regulation (Cambridge MA: NBER) Working Paper \#6104, July.

Chipty, Tasneem (1995), "Economic Effects of Quality Regulations in the Day Care Industry", American Economic Review, 85, May 1995, 419-424. 
Cohen, Andrew Milman and Freeborn, Beth A. and McManus, Brian. 2013. "Competition and Crowding Out in the Market for Outpatient Substance Abuse Treatment." International Economic Review, Vol. 54, Issue 1, pp. 159-184, 2013.

Currie, Janet and V. Joseph Hotz (2001) Accidents Will Happen? Unintentional Injury, Maternal Employment, and Child Care Policy, (Cambridge MA: NBER) Working Paper \#8090.

Currie, Janet, and Duncan Thomas. 1995. "Does Head Start Make a Difference?" American Economic Review 85 (3): 341-364.

Currie, Janet, and Duncan Thomas. 1999. "Does Head Start Help Hispanic Children?” Journal of Public Economics, 74 (2): 235-262.

Cutler, David M and Jonathan Gruber. 1996. "Does Public Insurance Crowd Out Private Insurance?" Quarterly Journal of Economics, 111(2): 391-430.

Dynarski, Susan. 2000. "Hope for Whom? Financial Aid for the Middle Class and Its Impact on College Attendance.” National Tax Journal, 53 (3): 629-661.

Eriksen, Michael D. \& Rosenthal, Stuart S., 2010. "Crowd out effects of place-based subsidized rental housing: New evidence from the LIHTC program," Journal of Public Economics, Elsevier, vol. 94(11-12), pages 953-966, December.

Fitzpatrick, Maria D. 2008. "Starting School at Four: The Effect of Universal Pre-Kindergarten on Children's Academic Achievement." The B.E. Journal of Economic Analysis \& Policy, 8 (1): Article 46.

Fitzpatrick, Maria D. 2010. "Preschoolers Enrolled and Mothers at Work? The Effects of Universal Prekindergarten.” Journal of Labor Economics, 28 (1): 51-85.

Fuller, Bruce, Susanna Loeb, Annelie Strath, and Bidemi Abioseh Carrol. 2004. "State Formation of the Child Care Sector: Family Demand and Policy Action." Sociology of Education, 77 (4): 337-358.

Gordon, Nora. 2004. "Do Federal Grants Boost School Spending? Evidence from Title I." Journal of Public Economics, 88 (9-10): 1771-1792.

Gormley Jr., William T., and Ted Gayer. 2005. "Promoting School Readiness in Oklahoma." Journal of Human Resources, 40 (3), 533-558.

Gormley Jr., William T., Ted Gayer, Deborah Phillips, and Brittany Dawson. 2005. “The Effects of Universal Pre-K on Cognitive Development." Developmental Psychology, 41 (6): 872884. 
Gruber, Jonathan, and Kosali Simon. 2008. "Crowd-Out Ten Years Later: Have Recent Public Insurance Expansions Crowded Out Private Health Insurance?" Journal of Health Economics, 27 (2): 201- 217.

Herbst, Chris M., and Erdal Tekin. 2010. "Child Care Subsidies and Child Development." Economics of Education Review, 29 (4): 618-638.

Hofferth, Sandra L. and Duncan D. Chaplin (1998) "State Regulations: and Child Care Choice", Population Research and Policy Review, 17: 111-140.

Hotz, V. Joseph and Rebecca Kilburn (1997), "Regulating Child Care: The Effects of State Regulations on Child Care Demand and its Cost", xerox, Dept. of Economics, UCLA, October 1997.

Hotz, V. Joseph and Rebecca Kilburn (2000), “The Effects of State Regulations on Child Care Prices and Choices", xerox, Dept. of Economics, UCLA, March 2000.

Hotz, V. Joseph, and Mo Xiao. 2011. "The Impact of Regulations on the Supply and Quality of Care in Child Care Markets." American Economic Review, 101 (5): 1775-1805.

Hungerman, Daniel M. 2005. "Are the Church and State Substitutes? Evidence from the 1996 Welfare Reform." Journal of Public Economics, 89(11): 2245-2267.

Johnson, A.D., Ryan, R.M. \& Brooks-Gunn, J, (2012) Child Care Subsidies: Do they impact the quality of care children experience? Child Development, 83(4) 1444-1461.

Knight, Brian. 2002. "Endogenous Federal Grants and Crowd-out of State Government Spending: Theory and Evidence from the Federal Highway Aid Program." American Economic Review, 92 (1): 71-92.

Kontos, Susan, Hui-Chin Hsu, and Loraine Dunn. 1994. "Children's Cognitive and Social Competence in Child-Care Centers and Family Day-Care Homes." Journal of Applied Developmental Psychology, 15 (3): 387-411.

Henry Levin and Heather Schwartz. 2007. "Educational Vouchers for Universal Preschools," Economics of Education Review, 26:3-16.

Long, Bridget Terry. 2004. "How do Financial Aid Policies Affect Colleges? The Institutional Impact of the Georgia HOPE Scholarship." Journal of Human Resources, 39 (4): 10451066.

Magnuson, Katherine A., Marcia K. Meyers, Christopher J. Ruhm, and Jane Waldfogel. 2004. "Inequality in Preschool Education and School Readiness." American Educational Research Journal, 41 (1): 115-157. 
Payne, A. Abigail. 2009. "Does Government Funding Change Behavior? An Empirical Analysis of Crowd Out." In Tax Policy and the Economy, edited by Jeffrey R. Brown and James M. Poterba, 159-184. Chicago: University of Chicago Press.

Peltzman, Sam. 1973. "Effect of Government Subsidies-in-Kind on Private Expenditures - Case of Higher Education." Journal of Political Economy, 81 (1): 1-27.

Ribar, David (1992), "Child Care and the Labor Supply of Married Women: Reduced Form Evidence", Journal of Human Resources 27 (1), Winter: 134-165.

Schweinhart, Lawrence J. 1993. Significant Benefits: The High/Scope Perry Preschool Study Through Age 27. Monographs of the High/Scope Educational Research Foundation, No. Ten. Missouri: High/Scope Educational Research Foundation.

Shonkoff, Jack P., and Deborah A. Phillips, eds. 2000. From Neurons to Neighborhoods: The Science of Early Childhood Development. Washington, DC: The National Academies Press.

Whitebook, Marcy, and Laura Sakai. 2003. “Turnover Begets Turnover: An Examination of Job and Occupational Instability among Child Care Center Staff." Early Childhood Research Quarterly, 18 (3): 273-293. 
Figure 1. Percent of Four Year Olds in Georgia Enrolled in the Georgia and Oklahoma Universal Pre-K Programs

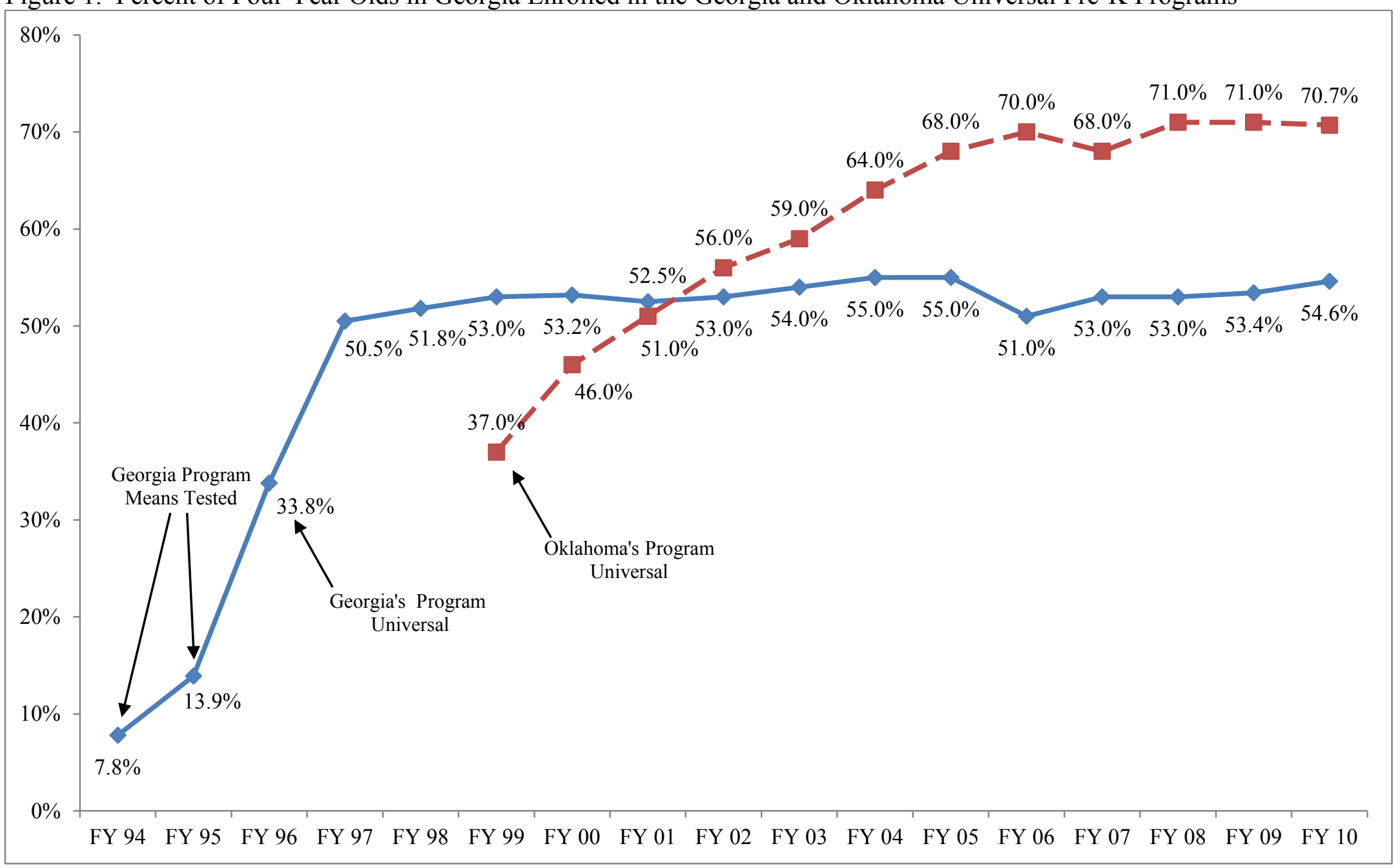

Notes: From Brackett, Henry and Weathersby (1999) and various web sources. A fiscal year runs from October of the previous year to September of the year in its name. For example, FY96 runs from October 1, 1995 to September 30, 1996. Percent of population of four year olds is calculated using the Census Bureau's Time Series of State Population Estimates by Age, which can be found. 
Figure 2. Difference-in-Difference Estimates of the Effects of Universal Pre-Kindergarten on Supply of Childcare in Georgia

Panel A. Total Number of Childcare Centers

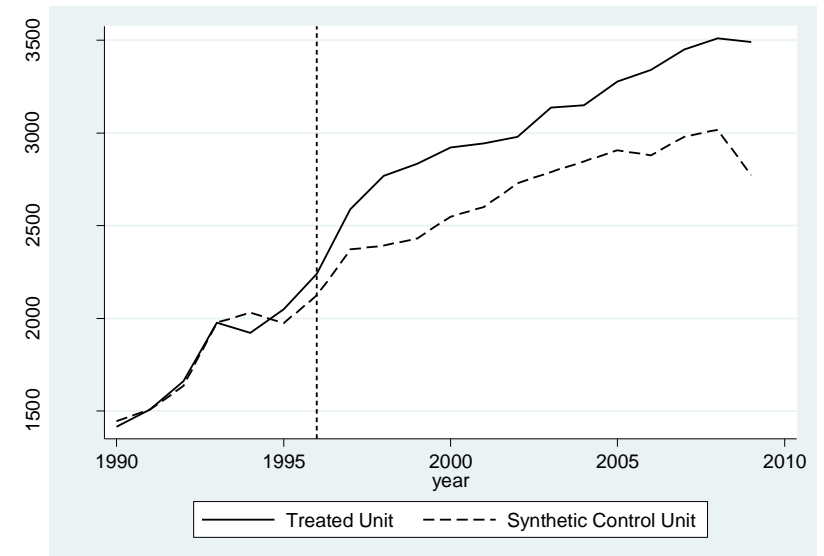

Panel B. Total Number of Childcare Center Employees

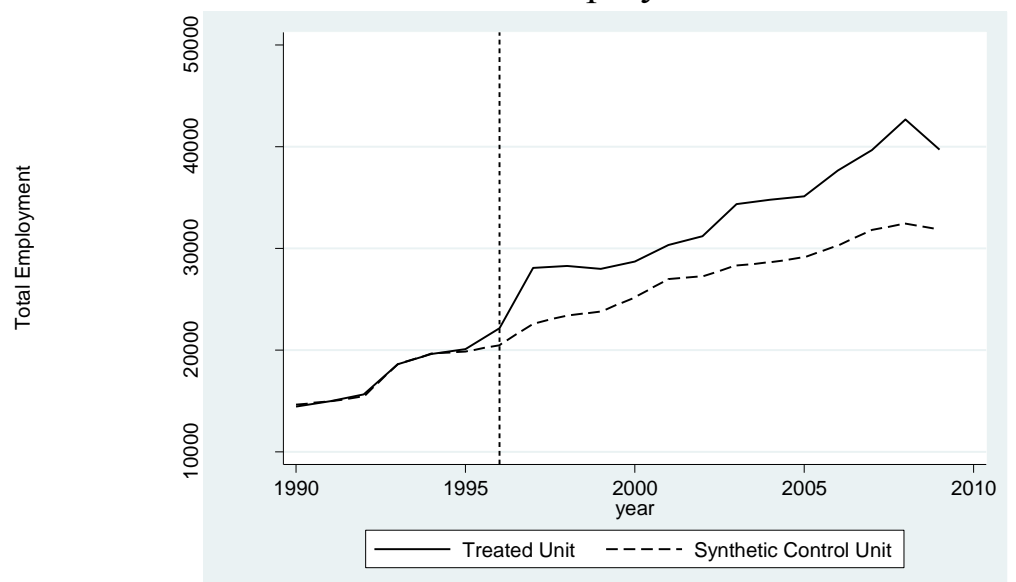

Panel C. Total Number of Private Centers

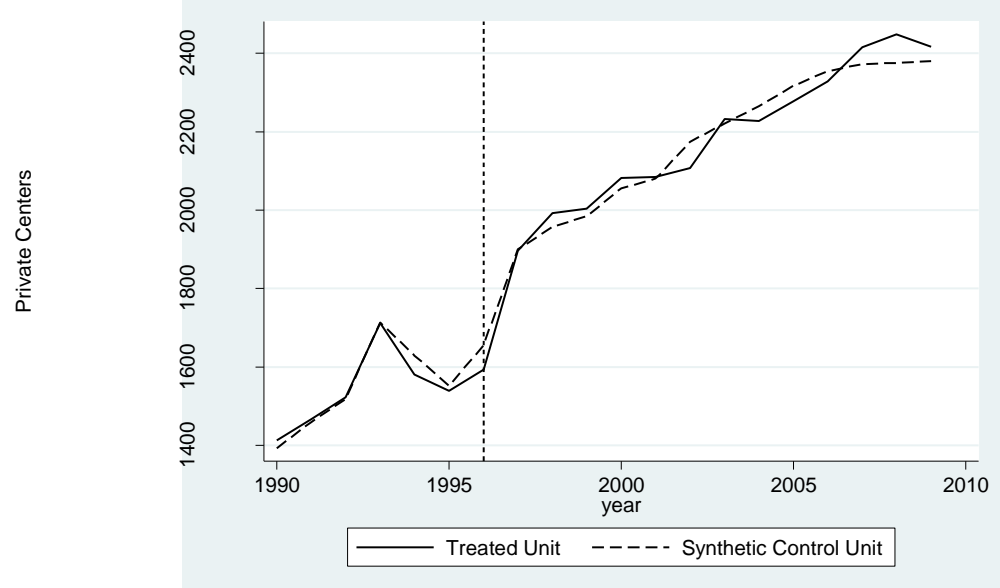




\section{Panel D. Total Number of Childcare Center Employees in Private Centers}

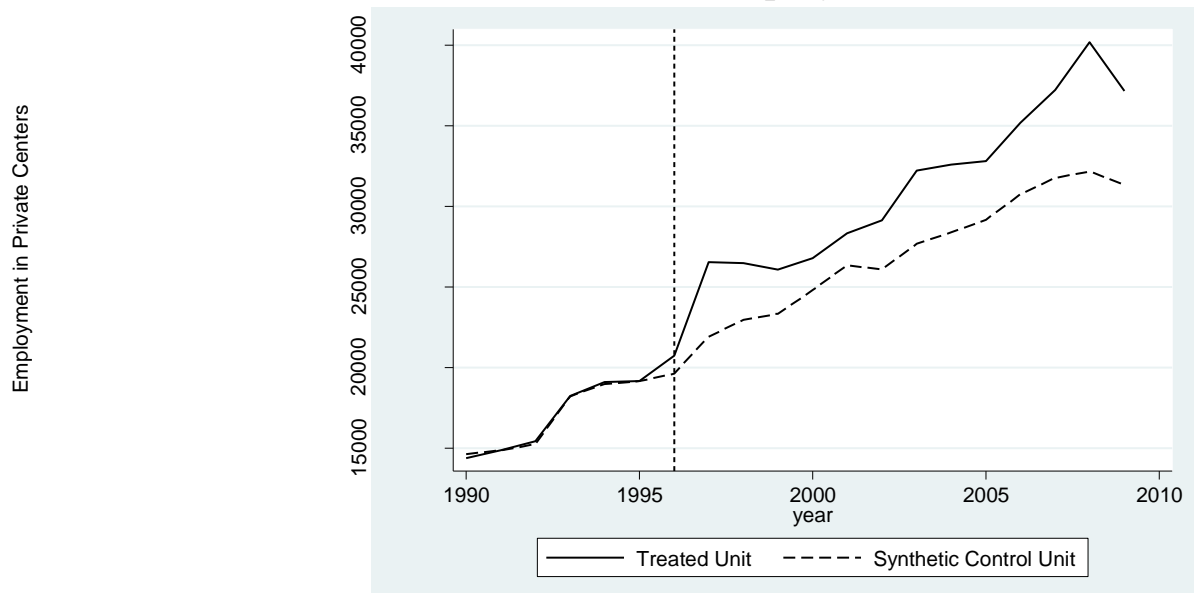

Panel E. Pay per Childcare Employee in the Private Sector $(\$ 1,000$ s)

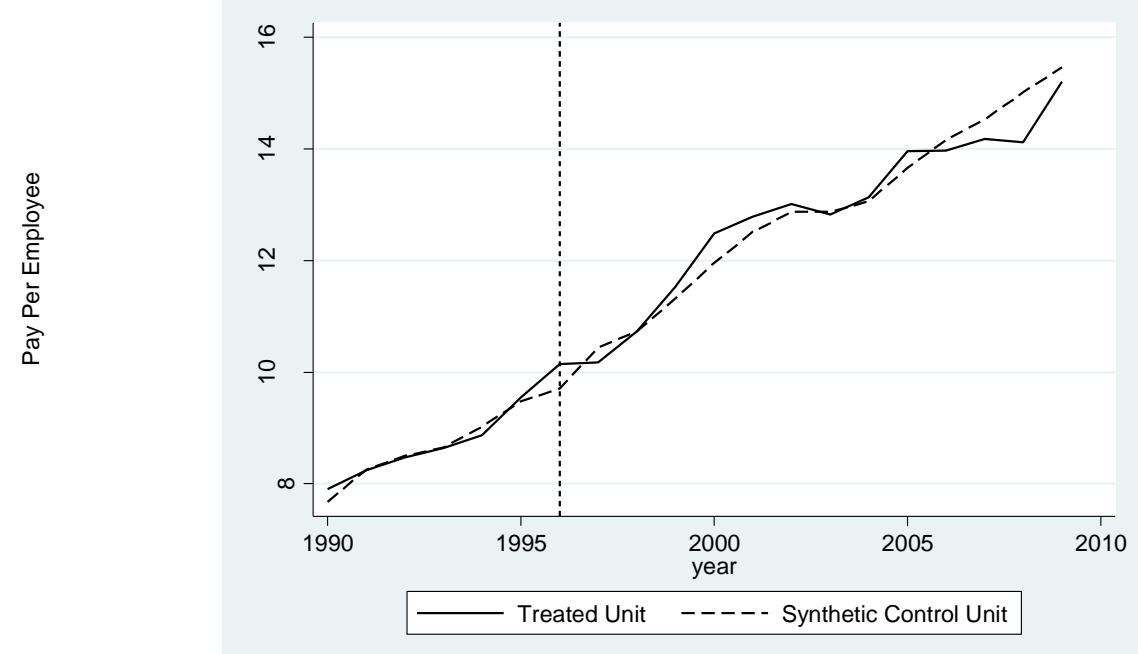

Note: Based on the authors calculations using data from the CBP and CCD. The figures depict the synthetic control group estimate of the difference in a given measure of supply for Georgia (solid line) and a synthetic control group created as described in the paper. 
Figure 3. Difference-in-Difference Estimates of the Effects of Universal Pre-Kindergarten on Supply of Childcare in Oklahoma

Panel A. Total Number of Childcare Centers

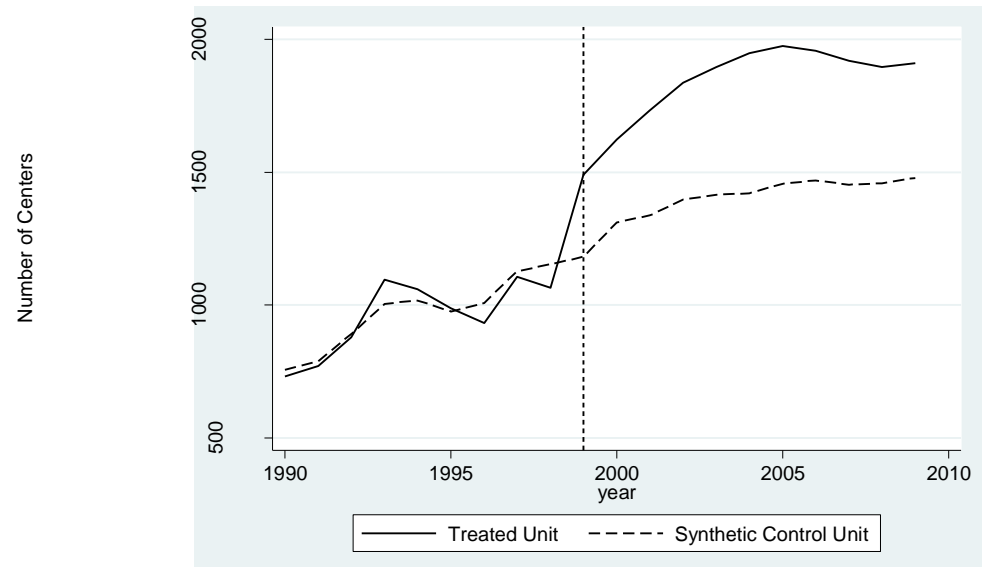

Panel B. Total Number of Childcare Center Employees

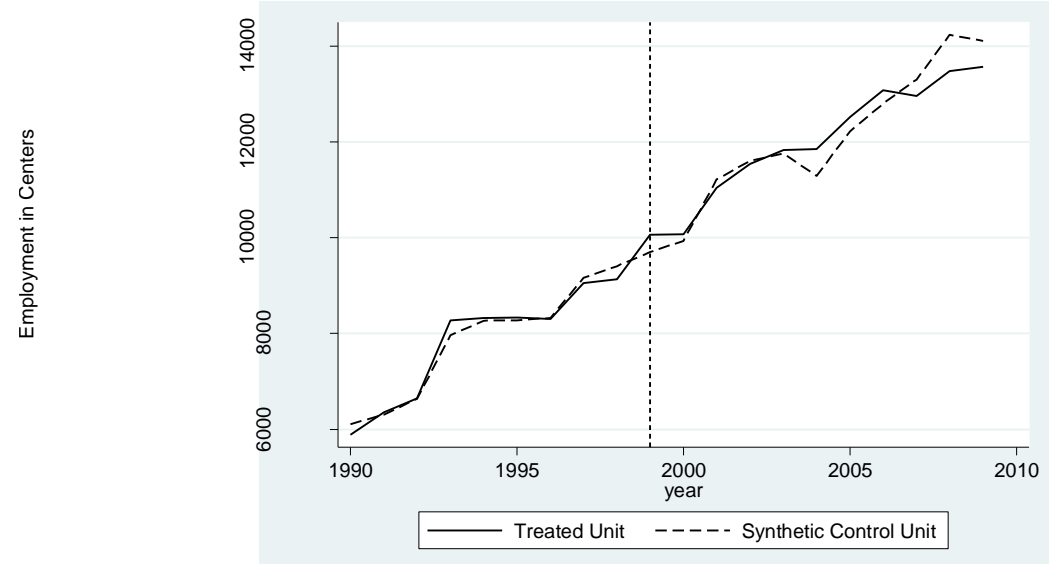

Panel C. Total Number of Private Centers

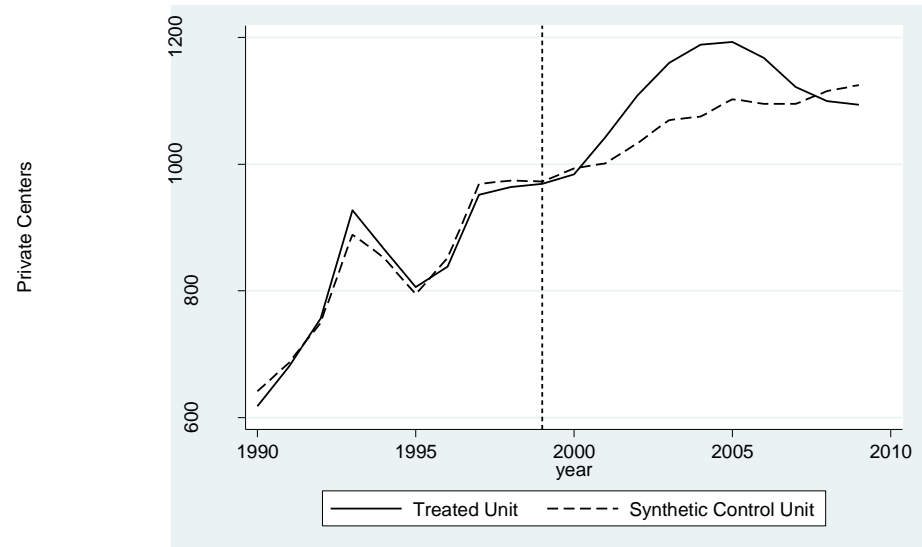




\section{Panel D. Total Number of Childcare Center Employees in Private Centers}

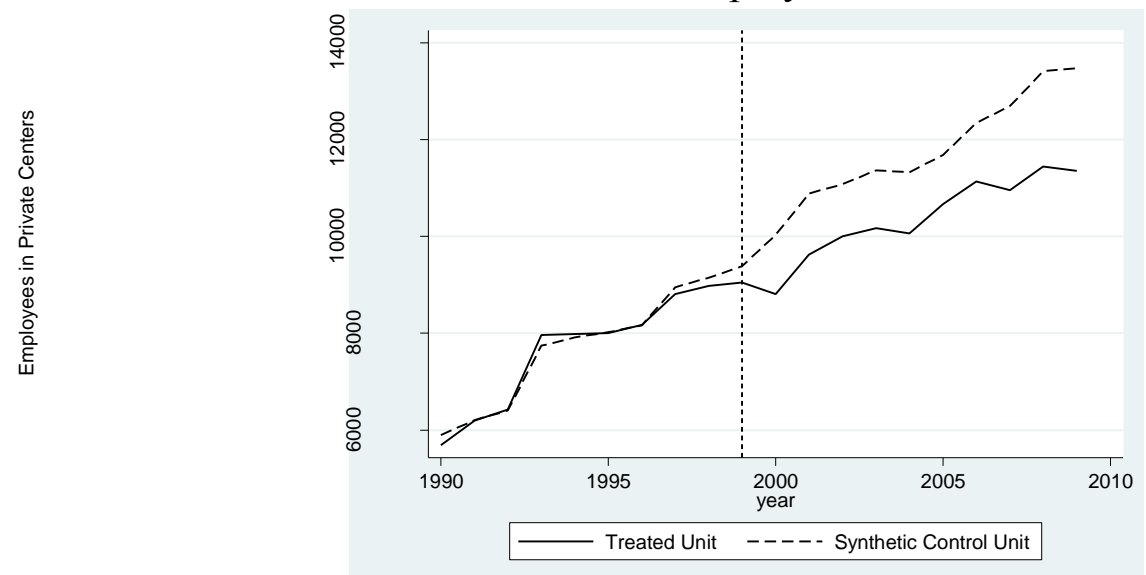

Panel E. Pay per Childcare Employee in the Private Sector

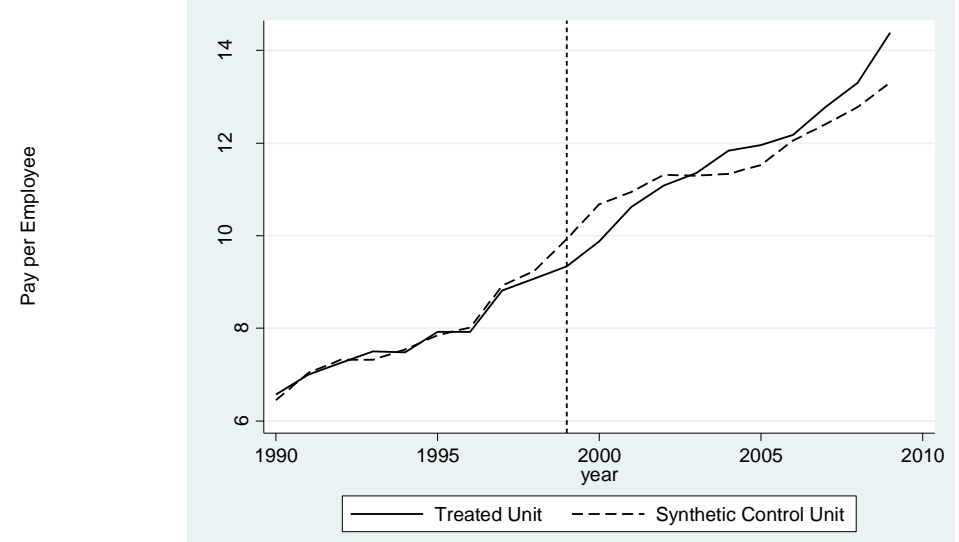

Note: Based on the authors calculations using data from the CBP and CCD. The figures depict the synthetic control group estimate of the difference in a given measure of supply for Oklahoma (solid line) and a synthetic control group created as described in the paper. 
Figure 4. Number of Universal Preschool Centers, by County, in Georgia

Panel A. 1994

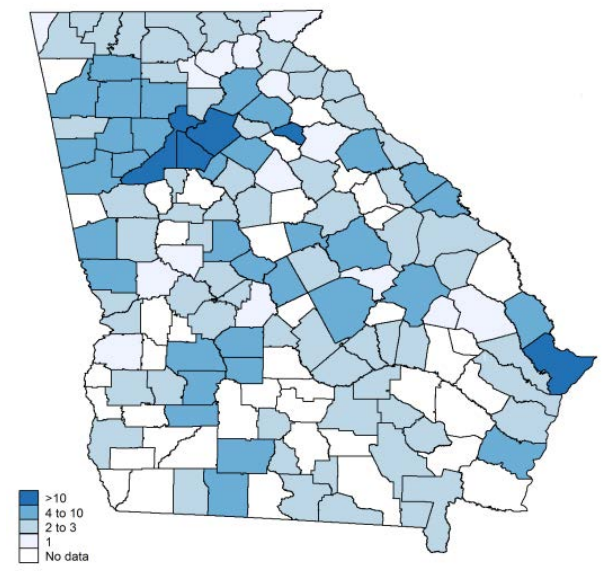

Panel B. 1998

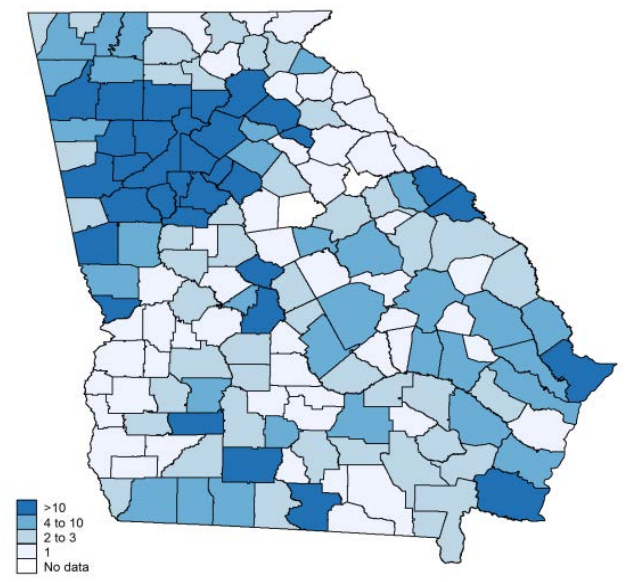

Panel C. 2002

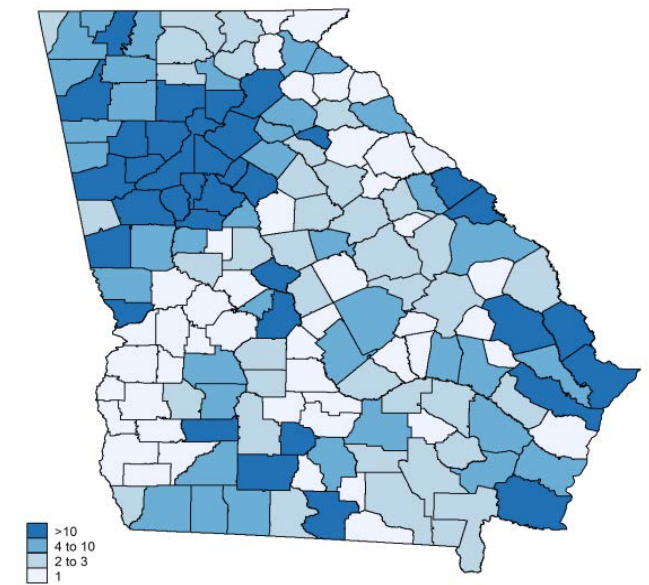

Panel D. 2005

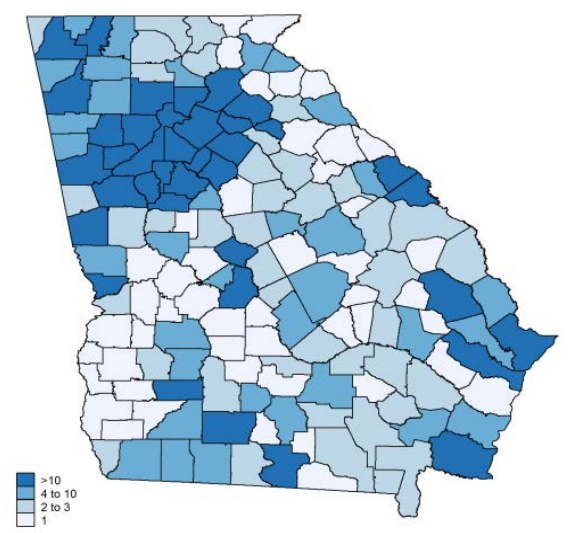

Note: Based on data compiled by the authors. 
Table 1. Average Number and Characteristics of Childcare Centers and Family Daycare Homes across Counties in Georgia and Oklahoma, 1990-2005

\begin{tabular}{|c|c|c|c|c|}
\hline \multirow[b]{2}{*}{ Outcome } & \multicolumn{2}{|c|}{ Georgia } & \multicolumn{2}{|c|}{ Oklahoma } \\
\hline & Mean & $\begin{array}{l}\text { Standard } \\
\text { Deviation }\end{array}$ & Mean & $\begin{array}{l}\text { Standard } \\
\text { Deviation }\end{array}$ \\
\hline Childcare Centers, Public and Private and Daycare Homes & 92 & 199 & 109 & 241 \\
\hline Childcare Centers, Public and Private & 19 & 40 & 20 & 41 \\
\hline Private Childcare Centers & 13 & 31 & 14 & 30 \\
\hline Daycare Homes & 73 & 160 & 89 & 201 \\
\hline Private and Public Childcare Center Employment & 191 & 500 & 136 & 365 \\
\hline Private Childcare Center Employment & 182 & 488 & 126 & 346 \\
\hline Private Childcare Center Payroll per Employee $(\$ 1,000$ s) & 8 & 5 & 6 & 3 \\
\hline Daycare Home Receipts $(\$ 1,000$ s) & 743 & 1,831 & 933 & 2,485 \\
\hline Number of Counties & 159 & & 77 & \\
\hline
\end{tabular}

Note: Based on the authors' calculations using the LBD, ILBD and CCD for 1990 to 2005. Averages and standard deviations across counties over the whole period reported separately for Georgia and Oklahoma. 
Table 2. Estimated Effect of Universal Pre-K Policy on Supply of Childcare in Georgia and Oklahoma

\begin{tabular}{lccc}
\hline & \multicolumn{3}{c}{ Panel A. Childcare Centers, Public and Private } \\
\hline UPK in Georgia & $244 * * *$ & $189 *$ & 374 \\
& $(82)$ & $(95)$ & $\{0.02\}$ \\
UPK in Oklahoma & $433^{* * *}$ & $431^{* * *}$ & 448 \\
& $(33)$ & $(52)$ & $\{0.06\}$ \\
\hline & Panel B. Childcare Center Employees, Public and Private \\
\hline UPK in Georgia & $5,531^{* * *}$ & $4,144^{* * *}$ & 5,443 \\
& $(913)$ & $(737)$ & $\{0.04\}$ \\
UPK in Oklahoma & -500 & -302 & -38 \\
& $(400)$ & $(412)$ & $\{0.45\}$ \\
\hline & & Panel C. Private Childcare Centers \\
\hline UPK in Georgia & 68 & 30 & 6 \\
UPK in Oklahoma & $(62)$ & $(67)$ & $\{0.47\}$ \\
& -29 & -18 & 22 \\
& $(22)$ & $(39)$ & $\{0.33\}$ \\
\hline
\end{tabular}

Panel D. Employees of Private Childcare Centers

\begin{tabular}{lccc}
\hline UPK in Georgia & $5,165^{* * *}$ & $3,834 * * *$ & 4,059 \\
& $(861)$ & $(777)$ & $\{0.04\}$ \\
UPK in Oklahoma & $-1,544 * * *$ & $-1,343 * * *$ & $-1,293$ \\
& $(386)$ & $(425)$ & $\{0.24\}$ \\
\hline
\end{tabular}

Panel E. Pay per Employee in Private Childcare Centers, \$1000s

\begin{tabular}{lccc}
\hline UPK in Georgia & -0.11 & -0.041 & -0.019 \\
& $(0.216)$ & $(0.133)$ & $\{0.56\}$ \\
UPK in Oklahoma & $-0.252^{* *}$ & $-0.598^{* *}$ & 0.119 \\
& $(0.113)$ & $(0.208)$ & $\{0.84\}$
\end{tabular}

\begin{tabular}{lccc}
\hline Comparison Group & All States & Southern States & Synthetic Control \\
\hline Number of Obs. & 1,019 & 340 &
\end{tabular}

Note: Based on the authors' calculations using the state-level CBP and the CCD for 1990 to 2005. Standard errors are in parentheses. Each row and column combination presents results for a separate differences-in-differences specification with the dependent variable given by the row header and the sample as listed in the bottom row. All columns include state and year fixed effects. Columns 3 and 5 include state specific time trends. The fifth column presents difference-in-difference estimates using the synthetic control group method of Abadie et al. (2010) with the corresponding probability levels from placebo tests of inference in brackets \{\}$.{ }^{* *}$ and $*$ represent estimates statistically significant at the 1 and 5 percent levels, respectively. 
Table 3. Estimated Effect of Universal Pre-K Provision in a Market on Supply of Childcare in Georgia

\begin{tabular}{lcc}
\hline & $(1)$ & $(2)$ \\
\hline & \multicolumn{2}{c}{ Childcare Centers, Public } \\
& \multicolumn{2}{c}{ and Private } \\
\hline UPK Centers & $0.358^{* *}$ & $0.389 * *$ \\
& $(0.115)$ & $(0.120)$ \\
\hline \multirow{2}{*}{ UPK Centers } & \multicolumn{2}{c}{ Private Childcare Centers } \\
& 0.219 & 0.228 \\
& $(0.123)$ & $(0.144)$ \\
\hline UPK Centers & \multicolumn{2}{c}{ Daycare Homes } \\
& -0.938 & -0.345 \\
& $(1.369)$ & $(1.469)$
\end{tabular}

Childcare Center

Employees, Public and

Private

\begin{tabular}{lcc}
\hline UPK Centers & 2.576 & 2.477 \\
& $(2.282)$ & $(2.690)$ \\
\hline & \multicolumn{3}{c}{ Employees of Private } \\
& Childcare & Centers \\
\hline UPK Centers & 2.312 & 2.229 \\
& $(2.340)$ & $(2.760)$ \\
\hline
\end{tabular}

Pay per Employee in

Private Childcare Centers, $\$ 1000 \mathrm{~s}$

\begin{tabular}{lcc}
\hline UPK Centers & -0.019 & -0.015 \\
& $(0.012)$ & $(0.015)$ \\
\hline Number of Observations & 2,226 & 2,226 \\
\hline Year Fixed Effects & Y & Y \\
County Fixed Effects & Y & Y \\
County Specific Time Trends & Y & Y \\
Community Characteristics & & Y
\end{tabular}

Note: Based on the authors' calculations using the county-level LBD, ILBD and CCD for Georgia from 1990 to 2005, where available. Each row and column combination represents estimates from a separate regression with the controls specified. Standard errors are in parentheses. $* *$ and $*$ represent estimates statistically significant at the 1 and 5 percent levels, respectively. The reported coefficients are for the effects of an additional center receiving universal preschool funds in a county on the supply measure reported in the row header. 
Table 4. Estimated Effect of Universal Pre-K Provision in a Market on Supply of Childcare in Oklahoma

\begin{tabular}{|c|c|c|}
\hline & (1) & (2) \\
\hline & \multicolumn{2}{|c|}{$\begin{array}{l}\text { Childcare Centers, Public } \\
\text { and Private }\end{array}$} \\
\hline \multirow[t]{3}{*}{ PK Schools } & $0.943 * *$ & $0.962 * *$ \\
\hline & $(0.057)$ & $(0.046)$ \\
\hline & \multicolumn{2}{|c|}{ Private Childcare Centers } \\
\hline \multirow[t]{3}{*}{ PK Schools } & -0.057 & -0.038 \\
\hline & $(0.057)$ & $(0.046)$ \\
\hline & \multicolumn{2}{|c|}{ Daycare Homes } \\
\hline \multirow[t]{3}{*}{ PK Schools } & $-7.248^{* *}$ & $-7.124 * *$ \\
\hline & $(1.468)$ & $(1.348)$ \\
\hline & \multicolumn{2}{|c|}{$\begin{array}{c}\text { Childcare Center } \\
\text { Employees, Public and } \\
\text { Private }\end{array}$} \\
\hline \multirow[t]{3}{*}{ PK Schools } & -0.719 & -0.555 \\
\hline & $(1.142)$ & $(1.051)$ \\
\hline & \multicolumn{2}{|c|}{$\begin{array}{l}\text { Employees of Private } \\
\text { Childcare Centers }\end{array}$} \\
\hline \multirow[t]{3}{*}{ PK Schools } & $-2.920^{*}$ & $-2.778^{*}$ \\
\hline & (1.298) & (1.223) \\
\hline & \multicolumn{2}{|c|}{$\begin{array}{l}\text { Pay per Employee in Private } \\
\text { Childcare Centers, } \$ 1000 \text { s }\end{array}$} \\
\hline \multirow[t]{2}{*}{ PK Schools } & -0.004 & -0.006 \\
\hline & $(0.011)$ & $(0.011)$ \\
\hline Number of Observations & 1,232 & 1,232 \\
\hline Year Fixed Effects & $\mathrm{Y}$ & $\mathrm{Y}$ \\
\hline County Fixed Effects & $\mathrm{Y}$ & $\mathrm{Y}$ \\
\hline County Specific Time Trends & $\mathrm{Y}$ & $\mathrm{Y}$ \\
\hline Community & & $\mathrm{Y}$ \\
\hline
\end{tabular}

Note: Based on the authors' calculations using the county-level LBD, ILBD and CCD for Oklahoma from 1990 to 2005, where available. Each row and column combination represents estimates from a separate regression with the controls specified. Standard errors are in parentheses. $* *$ and * represent estimates statistically significant at the 1 and 5 percent levels, respectively. The reported coefficients are for the effects of an additional center receiving universal preschool funds in a county on the supply measure reported in the row header. 
Table 5. Entry and Exit of Individual Childcare Centers in Georgia and Oklahoma

\begin{tabular}{|c|c|c|c|c|c|c|}
\hline & (1) & (2) & (3) & (4) & $(5)$ & $(6)$ \\
\hline & & Entry & & & Exit & \\
\hline & \multicolumn{6}{|c|}{ Panel A. Georgia } \\
\hline UPK Centers & $\begin{array}{c}-0.000176 \\
(0.000118)\end{array}$ & $\begin{array}{l}-2.31 \mathrm{e}-05 \\
(9.92 \mathrm{e}-05)\end{array}$ & $\begin{array}{l}-0.000110 \\
(0.000130)\end{array}$ & $\begin{array}{r}0.000346^{* *} \\
(5.56 \mathrm{e}-05)\end{array}$ & $\begin{array}{c}0.000355^{* *} \\
(5.66 \mathrm{e}-05)\end{array}$ & $\begin{array}{c}0.000371^{* *} \\
(5.94 \mathrm{e}-05)\end{array}$ \\
\hline \multirow[t]{2}{*}{ Number of Obs. } & \multicolumn{6}{|c|}{167,372} \\
\hline & \multicolumn{6}{|c|}{ Panel B. Oklahoma } \\
\hline PK Schools & $\begin{array}{c}-0.000108 \\
(0.000256)\end{array}$ & $\begin{array}{l}-0.000113 \\
(0.000243) \\
\end{array}$ & $\begin{array}{c}-5.88 \mathrm{e}-05 \\
(0.000257)\end{array}$ & $\begin{array}{c}2.13 \mathrm{e}-05 \\
(6.44 \mathrm{e}-05) \\
\end{array}$ & $\begin{array}{c}4.10 \mathrm{e}-05 \\
(6.80 \mathrm{e}-05) \\
\end{array}$ & $\begin{array}{c}4.03 e-05 \\
(7.83 e-05) \\
\end{array}$ \\
\hline Number of Obs. & \multicolumn{6}{|c|}{130,587} \\
\hline Year Fixed Effects & Y & $\mathrm{Y}$ & $\mathrm{Y}$ & $\mathrm{Y}$ & $\mathrm{Y}$ & $\mathrm{Y}$ \\
\hline County Fixed Effects & Y & Y & $\mathrm{Y}$ & $\mathrm{Y}$ & Y & $\mathrm{Y}$ \\
\hline County Specific Time Trends & Y & & $\mathrm{Y}$ & Y & & $\mathrm{Y}$ \\
\hline Community Characteristics & & $\mathrm{Y}$ & $\mathrm{Y}$ & & $\mathrm{Y}$ & $\mathrm{Y}$ \\
\hline
\end{tabular}

Note: Based on the authors' calculations using the firm-level LBD, ILBD and CCD for Georgia and Oklahoma from 1990 to 2005, where available. Each row and column combination represents estimates from a separate regression with the controls specified. Standard errors are in parentheses. * and ** represent estimates statistically significant at the 1 and 5 percent levels, respectively. The reported coefficients are for the effects of an additional center receiving universal preschool funds in a county on the supply measure reported in the row header. 
Table 6. Estimated Effects of Universal Preschool Provision on the Supply of Childcare in Different Communities in Georgia

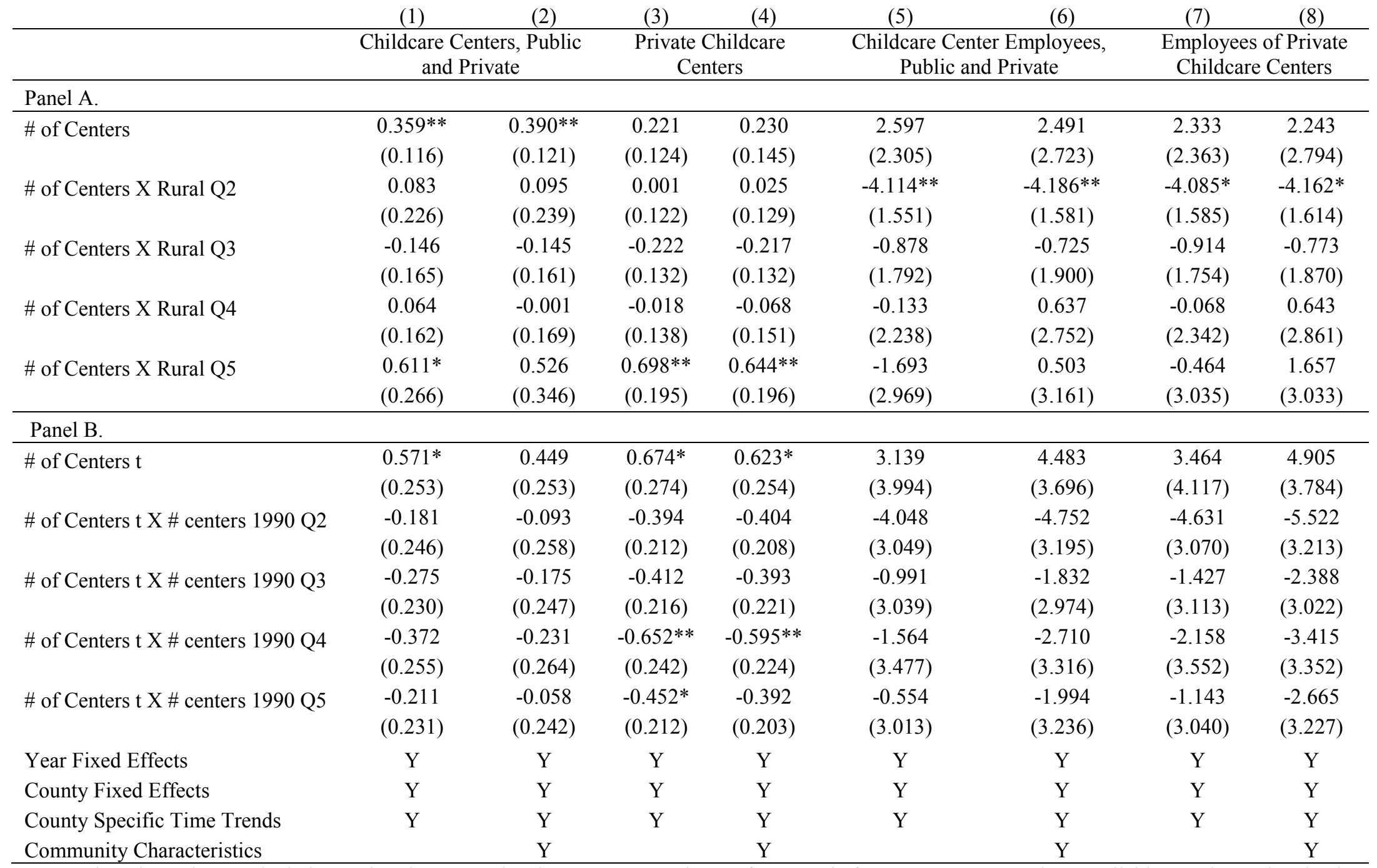

Note: Based on the authors' calculations using the county-level LBD, ILBD and CCD for Georgia from 1990 to 2005, where available. Each panel and column combination represents estimates from a separate regression with the controls specified. Standard errors are in parentheses. $*$ and $* *$ represent estimates statistically significant at the 1 and 5 percent levels, respectively. The reported coefficients are for the effects of an additional center receiving universal preschool funds in a county on the supply measure reported in the row header. The number of observations in each regression is 2,226. 
Appendix A. Measures of the Supply of Childcare in Treated States and Other Southern States Panel A. Total Number of Childcare Centers

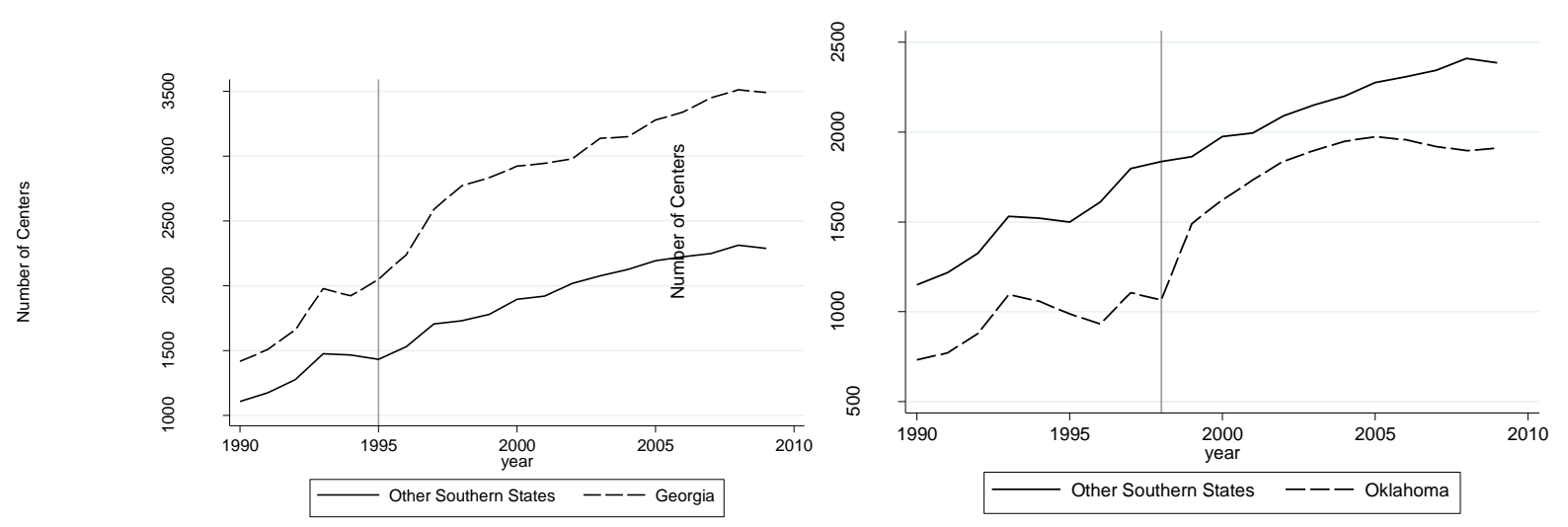

Panel B. Total Number of Childcare Center Employees
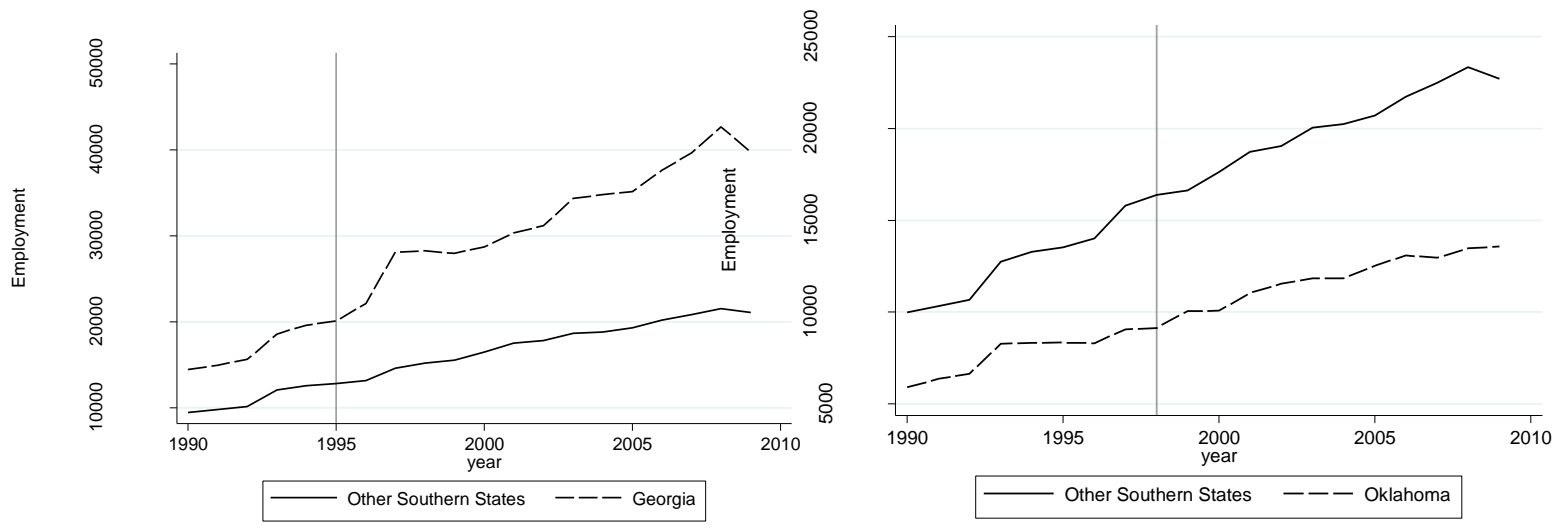

Panel C. Total Number of Private Centers
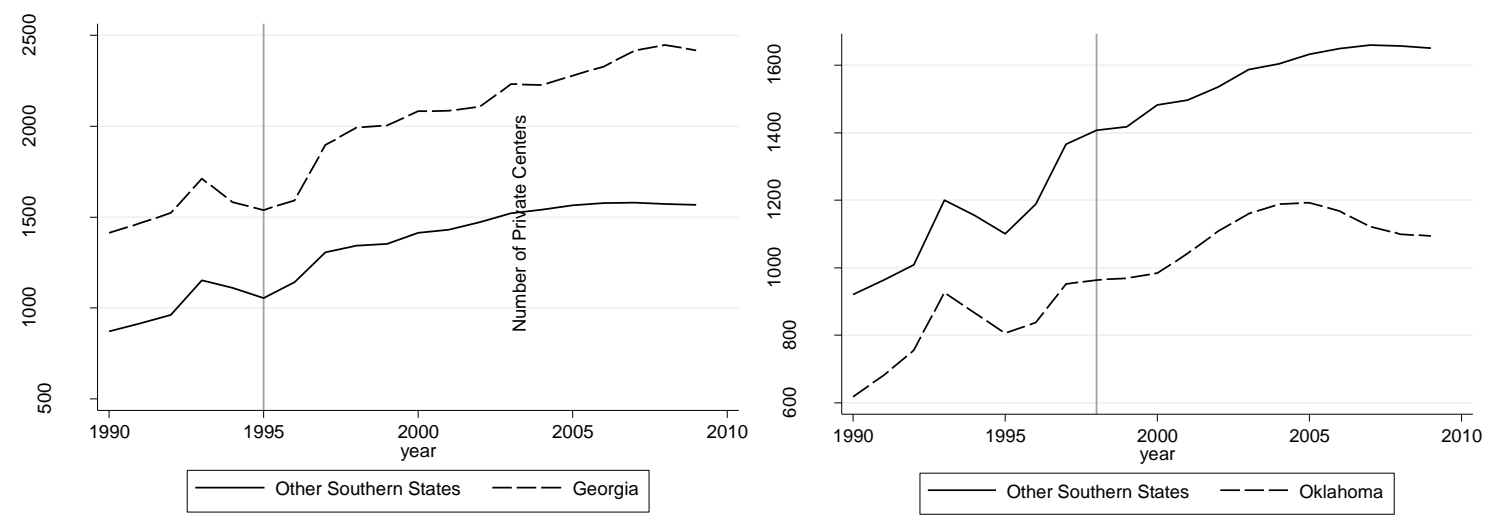


\section{Panel D. Total Number of Childcare Center Employees in Private Centers}
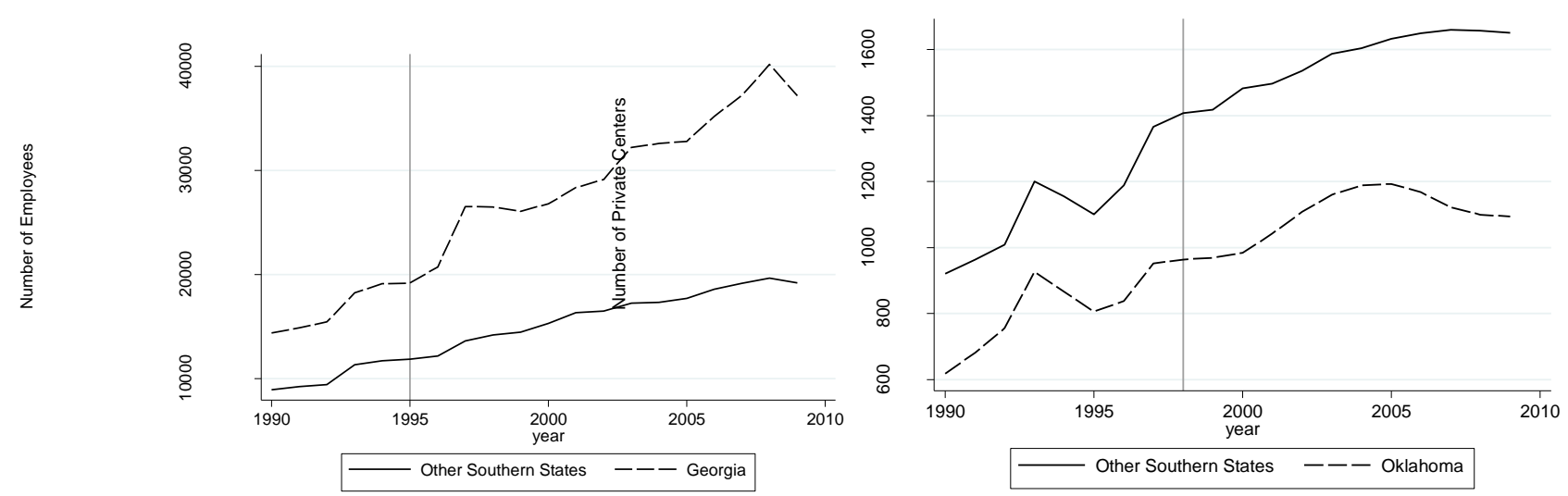

Panel E. Pay per Childcare Employee in the Private Sector $(\$ 1,000$ s)
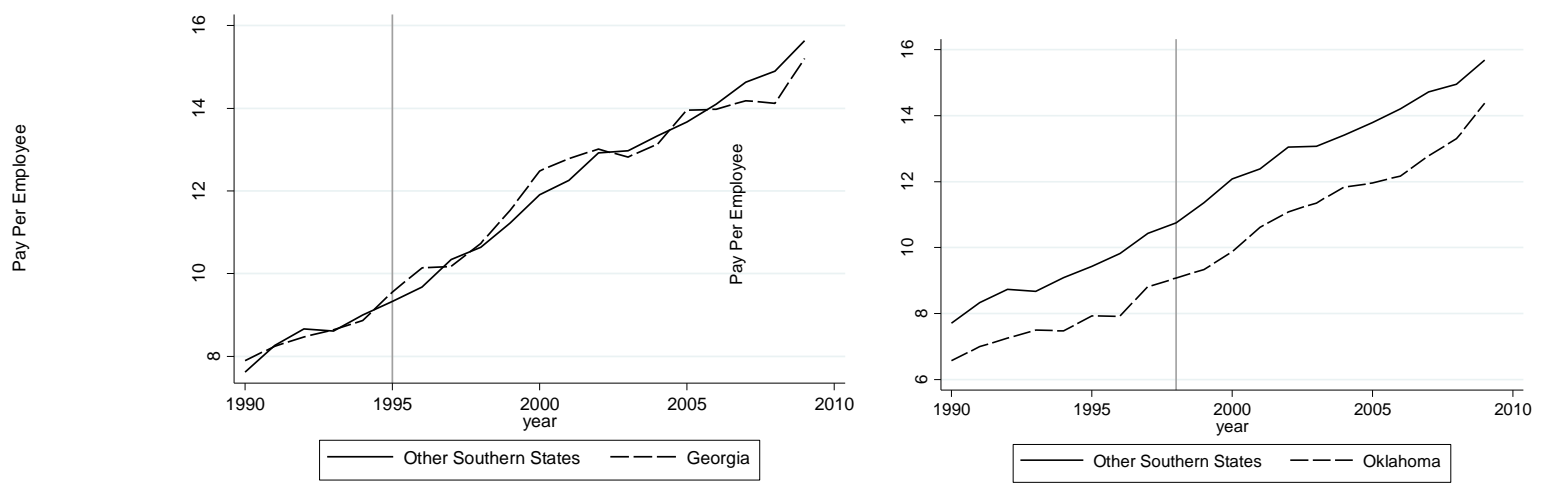

Note: Based on the authors calculations using data from the CBP and CCD. The figures depict the synthetic control group estimate of the difference in a given measure of supply for Georgia (solid line) and a synthetic control group created as described in the paper. 